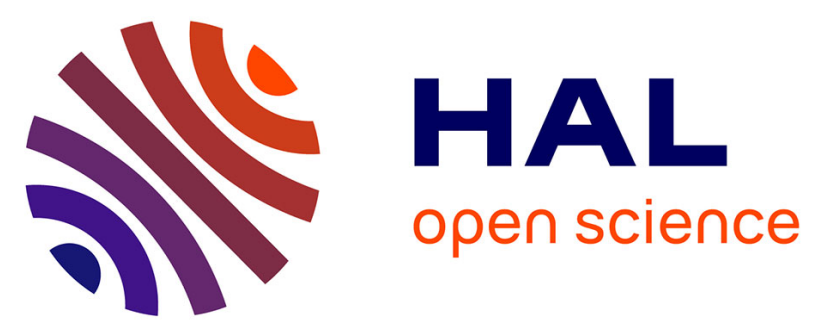

\title{
Evolution and maintenance of haploid-diploid life cycles in natural populations: the case of the marine brown alga Ectocarpus
}

Lucia Couceiro, Mickael Le Gac, Heather M. Hunsperger, Stéphane Mauger, Christophe Destombe, J. Mark Cock, Sophia Ahmed, Susana M Coelho, Myriam Valero, Akira F Peters

\section{To cite this version:}

Lucia Couceiro, Mickael Le Gac, Heather M. Hunsperger, Stéphane Mauger, Christophe Destombe, et al.. Evolution and maintenance of haploid-diploid life cycles in natural populations: the case of the marine brown alga Ectocarpus. Evolution - International Journal of Organic Evolution, 2015, 69 (7), pp.1808-1822. 10.1111/evo.12702 . hal-01167462

\section{HAL Id: hal-01167462 \\ https://hal.science/hal-01167462}

Submitted on $20 \mathrm{Jul} 2015$

HAL is a multi-disciplinary open access archive for the deposit and dissemination of scientific research documents, whether they are published or not. The documents may come from teaching and research institutions in France or abroad, or from public or private research centers.
L'archive ouverte pluridisciplinaire HAL, est destinée au dépôt et à la diffusion de documents scientifiques de niveau recherche, publiés ou non, émanant des établissements d'enseignement et de recherche français ou étrangers, des laboratoires publics ou privés. 


\section{Evolution and maintenance of haploid-diploid life cycles in}

\section{natural populations: the case of the marine brown alga}

\section{Ectocarpus}

Lucía Couceiro $^{1,7}$, Mickael Le Gac ${ }^{1,4}$, Heather M. Hunsperger ${ }^{1,5}$, Stéphane Mauger ${ }^{1}$, Christophe Destombe ${ }^{1}$, J. Mark Cock ${ }^{2}$, Sophia Ahmed ${ }^{2,6}$, Susana M. Coelho ${ }^{2}$, Myriam Valero ${ }^{1}$, and Akira F. Peters ${ }^{3}$

${ }^{1}$ CNRS, Sorbonne Universités, UPMC, UMI 3614, Evolutionary Biology and Ecology of Algae, Station Biologique de Roscoff, PUCCh, UACH, CS 90074, Place G. Tessier, 29688 Roscoff, France

${ }^{2}$ CNRS, Sorbonne Universités, UPMC, UMR 7139, Algal Genetics, Station Biologique de Roscoff, Place G. Tessier, 29688 Roscoff, France

${ }^{3}$ Bezhin Rosko, 29250 Santec, France

${ }^{4}$ Present address: Ifremer, DYNECO PELAGOS, 29280 Plouzané, France

${ }^{5}$ Present address: Department of Biology, University of Washington, Seattle, Washington

${ }^{6}$ Present address: Department for Plant Sciences, University of Leeds, Leeds, UK

${ }^{7}$ Corresponding author: luciacouceirolopez@gmail.com

Running title: Haploid-diploid life cycle of Ectocarpus spp.

Keywords: asexual reproduction, gametophyte, host specificity, niche differentiation, ploidy, seaweed, sporophyte

Number of words: 7274; number of tables: 4; number of figures: 3 


\section{Abstract}

The evolutionary stability of haploid-diploid life cycles is still controversial. Mathematical models indicate that niche differences between ploidy phases may be a necessary condition for the evolution and maintenance of these life cycles. Nevertheless, experimental support for this prediction remains elusive. In the present work, we explored this hypothesis in natural populations of the brown alga Ectocarpus. Consistent with the life cycle described in culture, E. crouaniorum in NW France and $E$. siliculosus in SW Italy exhibited an alternation between haploid gametophytes and diploid sporophytes. Our field data invalidated, however, the long-standing view of an isomorphic alternation of generations. Gametophytes and sporophytes displayed marked differences in size and, conforming to theoretical predictions, occupied different spatio-temporal niches. Gametophytes were found almost exclusively on the alga Scytosiphon lomentaria during spring while sporophytes were present year-round on abiotic substrata. Paradoxically, E. siliculosus in NW France exhibited similar habitat usage despite the absence of alternation of ploidy phases. Diploid sporophytes grew both epilithically and epiphytically, and this mainly-asexual population gained the same ecological advantage postulated for haploid-diploid populations. Consequently, an ecological interpretation of the niche differences between haploid and diploid individuals does not seem to satisfactorily explain the evolution of the Ectocarpus life cycle. 


\section{Introduction}

Sexual reproduction entails cyclic alternation between two ploidy levels, but the relative timing of syngamy and meiosis (giving rise to the duplicated and the reduced states, respectively) varies widely across the eukaryotic tree of life. Indeed, the time lag between these two events, as well as the occurrence of somatic development in multicellular organisms, define three basic types of sexual life cycle: diploid, where syngamy immediately follows meiosis and the organism spends almost its entire life as a diploid; haploid, where meiosis immediately follows syngamy and the organism spends nearly its entire life as a haploid; and haploid-diploid, where both events are separated in time and there is an alternation of haploid and diploid phases (see Valero et al. 1992 for a more detailed description of these and other, less common life cycles).

Sexual life cycles have been intriguing evolutionary biologists for decades (reviewed in Valero et al. 1992; Mable and Otto 1998; Coelho et al. 2007; Otto and Gerstein 2008). As nearly all metazoans develop somatically as diploids and the traditional view of plants also suggests a reduction of the haploid phase with increasing developmental complexity, early studies on life cycle evolution were guided by the idea of diploid superiority. Two main hypotheses, based on the genetic advantages of having two sets of homologous chromosomes, were thus advanced to explain the evolution of an extended diploid phase: the masking hypothesis (Crow and Kimura 1965) and the hypothesis of the higher rate of beneficial mutations (Paquin and Adams 1983). However, it soon became evident that the same arguments could also explain the evolution of haploid cycles under some circumstances (e.g., Crow and Kimura 1965; Otto and Goldstein 1992; Orr and Otto 1994; Jenkins and Kirkpatrick 1995; Otto 1996). Moreover, research on ploidy evolution conducted at the same time contradicted the supposed supremacy of diploids. First, the persistence of both haploid and diploid stages in a variety of taxa suggests that haploid-diploid life cycles are not a transitional state but an evolutionarily stable strategy (e.g., among the eukaryotic algae, Klinger 1993). Second, lengthening of the haploid phase accompanied by reduction of the diploid phase was also observed in certain 
groups - an unlikely scenario if diploidy were evolutionarily favoured (e.g., within the green algae, Otto 1996; and the brown algae, Bell 1997; Cock et al. 2014). Consequently, further research focused on the evolutionary stability of such diverse life cycles rather than on the evolution of diploidy as the sole successful strategy.

Under the genetic models mentioned above, transitions between haploid and diploid life cycles over evolutionary time can be interpreted as trade-offs between short-term individual-level benefits (diploidy) and longer-term advantages of more efficient selection (haploidy). Within a species, the relative importance of each strategy is determined by the frequency of recombination, the mating system, and the population structure of the species in question (Immler and Otto 2014). However, genetic models that confront the relative advantages of haploidy and diploidy consistently fail to predict the evolution of a shared haploid-diploid life history. Hence, explanations for the maintenance of both phases have frequently relied on ecological advantages of ploidy diversity rather than on genetic arguments (reviewed in Valero et al. 1992; Mable and Otto 1998; Coelho et al. 2007). In particular, one of the most widely evoked theories postulates that haploid-diploid species may exploit a broader range of environmental conditions as the two ploidy phases use different ecological niches. This argument, largely inspired by the heteromorphic life history of many haploiddiploid seaweeds, was advanced for the first time in the early 1980s (Stebbins and Hill 1980; Willson 1981) and gained considerable strength some decades later following its theoretical validation by Hughes and Otto (1999). These authors proved mathematically that such advantageous niche differentiation would indeed be a necessary condition for the evolution and subsequent maintenance of haploid-diploid life cycles. Namely, by drawing an analogy between the coexistence of isomorphic haploid and diploid individuals and the coexistence of two species competing for limited resources, they investigated the conditions under which an allele causing a haploid-diploid life cycle would invade either a haploid or a diploid population. As in the Lotka-Volterra model of interspecific competition (Lotka 1925; Volterra 1926), they found that some degree of niche differentiation between the two ploidy phases would prevent outcompetition of one phase by the 
other. Actually, using demographic data for the isomorphic red alga Gracilaria gracilis (as G. verrucosa, Destombe et al. 1989), they showed that even slight dissimilarities in the vital rates of haploids and diploids (such as fecundity, propagule survival and adult survival) were sufficient to allow spatio-temporal coexistence through conditional differentiation (i.e., one ploidy phase performs best under a particular set of conditions while the other phase is superior under a different set and, thus, coexistence becomes possible in a varying environment; Hughes and Otto 1999).

This theory is apparently well supported by a large and phylogenetically diverse group of heteromorphic organisms where haploids and diploids exhibit marked morphological divergence together with clear ecological differences. For instance, ecological differences between a resting stage resistant to biotic or abiotic stress and a fast-growing stage have been recorded for haploiddiploid yeasts (e.g., Coluccio et al. 2008), coccolithophores (e.g., Frada et al. 2008), brown algae (e.g., Carney and Edwards 2006), and red algae (e.g. Vergés et al. 2008). However, empirical evidence is much more limited for many other organisms exhibiting isomorphic, haploid-diploid life cycles like brown, red, and green seaweeds. In fact, haploid and diploid individuals in this last group not only look identical but also often overlap in space and time. Because of the inherent problem of distinguishing both types of individuals, ecological differentiation between isomorphic ploidy phases has been frequently explored through laboratory assays on previously-characterized material. Still, the task is not straightforward and an overwhelming majority of these studies has focused on a small number of species within a few orders of red algae (reviewed in Thornber 2006). Moreover, while these laboratory assays have commonly succeeded in demonstrating some degree of differentiation, results varied considerably depending on the target species and the particular factor tested (Thornber 2006). Field studies dealing with isomorphic species are even more restricted in their taxonomic scope and mainly involve demographic surveys on haploid:diploid ratios. Results from these surveys are again somewhat mixed and either haploid-dominated populations (e.g., PachecoRuíz and Zertuche-González 1999), diploid-dominated populations (e.g., Polifrone et al. 2012), or populations showing similar proportions of both ploidy phases (e.g., Destombe et al. 1989) have 
been reported. Furthermore, uneven ploidy ratios have frequently been interpreted in terms of phase-specific differences in mortality and reproductive output; yet, in many cases, such differences between phases were not clearly identified or were inconsistent with predictions (Fierst et al. 2005).

The recent emergence of Ectocarpus sp. as a model organism for the brown algae provides a unique opportunity to expand upon previous research. Indeed, since its proposal one decade ago (Peters et al. 2004), the Ectocarpus sp. genome has been sequenced and annotated (Cock et al. 2010b), giving access to a wide array of molecular tools that are being used to study its biology in general and its life cycle in particular (see, for example, the special issue of New Phytologist, Cock et al. 2010a). Studies on Ectocarpus reproduction date back to the end of the nineteenth century (Berthold 1881; Knight 1930; Papenfuss 1933, 1935) but the Ectocarpus life cycle was fully described for the first time in 1967 under laboratory conditions using E. siliculosus material collected in Naples, Italy (Müller 1967). Briefly, this haploid-diploid life cycle involves an alternation between diploid sporophytes, which produce spores by meiosis, and haploid, dioicous gametophytes, which produce gametes by mitosis (Fig. 1). Since gametophytes and sporophytes display similar, relatively simple morphologies under laboratory conditions, the genus has been traditionally defined as near-isomorphic (as compared with the strongly heteromorphic life cycles of other brown algae, characterized by macroscopic sporophytes and microscopic gametophytes). Nonetheless, at least in some strains, both phases can be distinguished in culture on the basis of differences during early development: sporophytes form compact thalli firmly attached to the substratum whereas gametophytes have a more feathery appearance (Peters et al. 2008).

Here, the life cycle of Ectocarpus was investigated under field conditions with the aim of determining whether the niche partitioning hypothesis advanced by Hughes and Otto (1999) can adequately explain the evolution and subsequent maintenance of haploid-diploid life cycles. To accomplish this goal, we conducted an extensive spatio-temporal survey of natural populations of both $E$. crouaniorum and E. siliculosus at a locality in NW France. Field material was collected from ten sites 
along a shoreline gradient during three consecutive years and, after recording relevant ecological information, all samples were comprehensively characterized in the laboratory using molecular tools. Moreover, during one season, E. siliculosus was also sampled in Naples, Italy (the locality of classical Ectocarpus life history studies, Berthold 1881; Müller 1964, 1967, 1976). Like previous studies testing the niche partitioning hypothesis, we explored the prediction of ecological differences between haploids and diploids. However, we also examined other, less-frequently addressed aspects of this hypothesis such as the nature of the putative ecological differences. Consequently, three different scenarios can be envisaged: (1) No ecological differences are detected between ploidy phases and, therefore, the niche partitioning hypothesis is rejected. (2) Ecological differences between ploidy phases are detected but these differences are not a direct outcome of ploidy level; in this case, the most probably explanation would be that the differences have evolved after the establishment of the haploid-diploid life cycle and, therefore, the niche partitioning hypothesis can explain the maintenance of haplo-diploidy but not its initial evolution. (3) Ecological differences between ploidy phases are detected and, moreover, these differences are a direct outcome of ploidy level; in this case, we would conclude that the niche partitioning hypothesis can not only explain the maintenance of haplo-diploidy but also its initial evolution.

\section{Materials and Methods}

\section{SAMPLING LOCALITIES, FIELD COLLECTIONS AND CULTURE ISOLATION}

Sampling was carried out repeatedly between 2010 and 2012 at Perharidy, close to the Roscoff Marine Biological Station (NW France; henceforth referred to as "Roscoff"), and once in March 2012 at Naples (SW Italy). In Roscoff, ten sites differing both in terms of their vertical position in the intertidal zone and in wave exposure were chosen according to the presence of Ectocarpus spp. in previous years (Peters et al. 2010b; Fig. S1, Table 1). In Naples, Ectocarpus was only found in the harbour of Mergellina (Fig. S1, Table 1). Collections at both localities involved (i) the isolation of macroscopic individuals resembling Ectocarpus that were epiphytic on other macrophytes 
(henceforth "epiphytic samples"), as well as (ii) the collection of abiotic substrata such as small pebbles and empty shells with or without visible algal turfs (henceforth "epilithic samples"). As field thalli may consist of more than a single individual, clonal cultures were generated from each isolate: fragments of a few cells from thalli morphologically identified as Ectocarpus (i.e., showing ribbonshaped plastids, Peters and Ramírez 2001) were inoculated in half-strength Provasoli-enriched

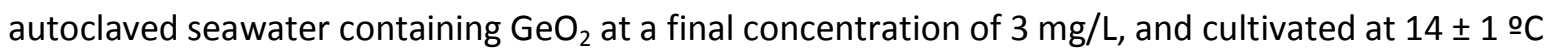
under 10-30 $\mu \mathrm{mol}$ photons $\mathrm{m}^{-2} \mathrm{~s}^{-1}$ of white light and a photoperiod of $10: 14$ (light : dark) (Peters et al. 2010b). After 2-6 weeks, thalli were transferred to new medium without $\mathrm{GeO}_{2}$. If eukaryotic contamination was detected, a sub-clone was generated from a thallus fragment consisting of a small number of cells. Germlings developing from cryptic stages on substratum samples were obtained by first cultivating the substratum for 1-2 months in medium without $\mathrm{GeO}_{2}$, followed by isolation of Ectocarpus clones as described above (Peters et al. 2015).

\section{TAXONOMIC IDENTITY, PLOIDY, AND SEX}

Once cultures attained enough biomass for DNA extraction, samples were lyophilized and total DNA was extracted using the NucleoSpin ${ }^{\circledR} 96$ Plant Kit (Macherey-Nagel, Düren, Germany). The taxonomic identity of each sample was determined at the species level using a two-fold approach. First, a fragment containing the ITS1 region together with 224 bp of the flanking genes $18 \mathrm{~S}$ and $5.8 \mathrm{~S}$ was amplified using the primers described by Peters et al. (2010a). PCR reactions were performed in a total volume of $15 \mu \mathrm{L}$ containing $0.5 \mu \mathrm{M}$ of each primer, $150 \mu \mathrm{M}$ of each dNTP, $4 \mathrm{mM}$ of $\mathrm{MgCl}_{2}, 1 \mathrm{x}$ GoTaq $^{\circledR}$ Flexibuffer, 0.53 units of GoTaq ${ }^{\circledR}$ FlexiDNA polymerase (Promega Corporation, Madison, WI, USA), and $2 \mu \mathrm{L}$ of 1:30 diluted template DNA. Cycling conditions included an initial denaturation step at $94{ }^{\circ} \mathrm{C}$ for $4 \mathrm{~min}$, followed by 30 cycles at $94{ }^{\circ} \mathrm{C}$ for $30 \mathrm{~s}, 53^{\circ} \mathrm{C}$ for $30 \mathrm{~s}$, and $72{ }^{\circ} \mathrm{C}$ for $1 \mathrm{~min}$, and a final extension at $72{ }^{\circ} \mathrm{C}$ for $2 \mathrm{~min}$. The length of this fragment, which has been shown to be diagnostic of different Ectocarpus species including the species previously recorded in Brittany (Peters et al. 2010a; Peters et al. 2010b), was determined by electrophoretic size separation in $2 \%$ agarose gels 
stained with ethidium bromide. Second, identification based on ITS1 length was verified by amplifying a fragment of the mitochondrial genome, with species-specific primers annealing in the rps14-atp8 spacer region. PCR reactions were performed in a total volume of $15 \mu \mathrm{L}$ containing 0.5 $\mu \mathrm{M}$ of each primer, $150 \mu \mathrm{M}$ of each dNTP, $2 \mathrm{mM}$ of $\mathrm{MgCl}_{2}, 1 \times \mathrm{GoTaq}^{\circledR}$ Flexibuffer, 0.53 units of GoTaq $^{\circledR}$ FlexiDNA polymerase, and $2 \mu \mathrm{L}$ of 1:30 diluted template DNA. Cycling conditions included an initial denaturation step at $94{ }^{\circ} \mathrm{C}$ for $5 \mathrm{~min}$, followed by 30 cycles at $94{ }^{\circ} \mathrm{C}$ for $30 \mathrm{~s}, 48{ }^{\circ} \mathrm{C}$ for $30 \mathrm{~s}$, and $72{ }^{\circ} \mathrm{C}$ for $45 \mathrm{~s}$, and a final extension at $72{ }^{\circ} \mathrm{C}$ for $10 \mathrm{~min}$. The presence/absence of rps 14 -atp 8 spacer PCR products was determined on $2 \%$ agarose gels. Primer sequences as well as expected sizes of the amplified fragments for both nuclear and mitochondrial markers are provided as supplementary material (Table S1).

Two fragments within the male and female sex-determining regions (Ahmed et al., 2014) were also amplified for all samples. In Ectocarpus, sex is expressed during the haploid phase (UV system) and, therefore, both regions are present in the diploid sporophytes while the haploid gametophytes carry either the male or the female one. PCR reactions were performed individually in a total volume of 10 $\mu \mathrm{L}$ containing $0.5 \mu \mathrm{M}$ of each primer, $150 \mu \mathrm{M}$ of each dNTP, $2 \mathrm{mM}$ of $\mathrm{MgCl}_{2}, 1 \times \mathrm{GoTaq}^{\circledR}$ Flexibuffer, 0.53 units of GoTaq ${ }^{\circledR}$ FlexiDNA polymerase, and $2 \mu \mathrm{L}$ of 1:30 diluted template DNA. The PCR program included a denaturation step at $94{ }^{\circ} \mathrm{C}$ for $4 \mathrm{~min}$, followed by 10 cycles of a touchdown $\left(94{ }^{\circ} \mathrm{C}\right.$ for $30 \mathrm{~s}$, $64{ }^{\circ} \mathrm{C}$ for $30 \mathrm{~s}$, and $72{ }^{\circ} \mathrm{C}$ for $30 \mathrm{~s} ; 1^{\circ} \mathrm{C}$ decrease of the annealing temperature every cycle), 25 additional cycles $\left(94{ }^{\circ} \mathrm{C}\right.$ for $30 \mathrm{~s}, 55^{\circ} \mathrm{C}$ for $30 \mathrm{~s}$, and $72{ }^{\circ} \mathrm{C}$ for $30 \mathrm{~s}$ ) and a final elongation step at $72{ }^{\circ} \mathrm{C}$ for 5 min. Positive/negative amplifications were checked on $2 \%$ agarose gels.

\section{ASEXUAL REPRODUCTION}

A panel of 13 microsatellites, selected from the markers used to construct the Ectocarpus genetic map (Heesch et al. 2010), was amplified in all samples. Depending on the locus, either individual or multiplex PCR reactions were performed in a total volume of $10 \mu \mathrm{L}$ containing varying concentrations of primers, $150 \mu \mathrm{M}$ of each dNTP, $2 \mathrm{mM}$ of $\mathrm{MgCl}_{2}, 1 \times \mathrm{GoTaq}^{\circledR}$ Flexibuffer, 0.35 units of $\mathrm{GoTaq}^{\circledR}$ 
FlexiDNA polymerase, and $2 \mu \mathrm{L}$ of 1:30 diluted template DNA (Table S1). Cycling conditions included an initial denaturation step at $94{ }^{\circ} \mathrm{C}$ for $5 \mathrm{~min}$, followed by 30 (multiplexes 1,2 , and 4 ) or 35 (multiplex 3 ) cycles at $94{ }^{\circ} \mathrm{C}$ for $30 \mathrm{~s}, 55^{\circ} \mathrm{C}$ for $30 \mathrm{~s}$, and $72{ }^{\circ} \mathrm{C}$ for $30 \mathrm{~s}$, and a final extension at $72{ }^{\circ} \mathrm{C}$ for 10 min. PCR products were diluted (1:10) and $2 \mu \mathrm{L}$ were added to a mixture containing $9.5 \mu \mathrm{L}$ of Hi-Di formamide (Life Technologies Corporation, Carlsbad, CA, USA) and 0.5 $\mu$ L of SM594 size standard (Mauger et al. 2012). This loading mix was denatured ( $95^{\circ} \mathrm{C}$ for $5 \mathrm{~min}$ ) and run in a 3130XL Genetic Analyzer (Life Technologies Corporation).

Microsatellite genotypes were scored manually using GeneMapper ${ }^{\circledR}$ ver. 4 software (Life Technologies Corporation) and samples missing data were re-amplified up to three times. Whenever possible, the frequency of null alleles was directly estimated from the haploid individuals and compared with the estimated frequencies in diploid individuals provided by the software Microchecker (Van Oosterhout et al. 2004). Only individuals showing amplification at seven or more loci were retained for further analysis.

In order to estimate the level of asexual reproduction in both haploid and diploid phases, we followed the sequential flowchart proposed by Halkett et al. (2005). First, the number of repeated multilocus genotypes was computed in GenAlex ver. 6.41 (Peakall and Smouse 2006). Because the observation of identical multilocus genotypes can either be the result of sampling the same clone (i.e., asexual origin) or two different genotypes which nonetheless share the same alleles for all studied loci (i.e., sexual origin), we also used GenClone 2.0 to test the efficiency of our microsatellite panel to estimate genotypic diversity (Arnaud-Haond and Belkhir 2007). By employing a jackknife subsampling procedure, this software recalculates the number of distinct multilocus genotypes that can be detected for all possible combinations of loci - from 1 to $L$, where $L$ is the number of analysed loci-; if an asymptote is reached with a number of loci $\leq L$, one may conclude that the number of loci analysed is enough to discriminate the genotypic diversity of the particular dataset. Moreover, this software also computes the probability of a given multilocus genotype to be observed in $N$ 
samples as a consequence of different sexual reproductive events rather than asexual reproduction (i.e., $\mathrm{P}_{\text {sex }}$ ). Further evidence regarding the asexual origin of the repeated multilocus genotypes was obtained by amplifying three additional loci. Finally, an estimate of clonal diversity $(R=(G-1) /(N-1)$, where $G$ is the number of distinct genotypes and $N$ is the total number of sampled individuals; Dorken and Eckert 2001) was calculated using both the initial and the extended microsatellite panel. The second approach to check the occurrence of asexual reproduction based on the theoretical prediction of non-random associations between loci when clonality dominates. Linkage disequilibrium was computed across all possible pairings of loci using the software GenePop ver. 4.2 (Raymond and Rousset 1995) and significance was tested by 1000 permutations followed by sequential Bonferroni correction (Rice 1989). Also, a single multilocus measure, the association index $\bar{r}_{\mathrm{d}}$, was computed using the software MultiLocus (Agapow and Burt 2001) and departure from random associations between loci was tested by comparing the observed dataset with 1000 simulated datasets. Since a recent expansion of some genotypes will increase linkage disequilibrium, both analyses were repeated after removing duplicate genotypes.

\section{STATISTICAL ANALYSES OF GAMETOPHYTE/SPOROPHYTE NICHE PREFERENCES}

A generalized linear model (GLM) with logistic regression was used to explore whether gametophytes and sporophytes were evenly distributed between epilithic and epiphytic samples or, whether each phase occupied a different substratum. However, since a large number of both gametophytes and sporophytes was only sampled for E. crouaniorum in the locality of Roscoff and E. siliculosus in the locality of Naples (E. crouaniorum was absent in Naples whereas E. siliculosus in Roscoff exhibited almost exclusively sporophytes; see the Results section below), species and locality effects were confounded in this model (dependent variable: life cycle phase; first explanatory variable: substratum; second explanatory variable: species/locality). In a second round, the same model was constructed considering only the E. siliculosus dataset (dependent variable: life cycle phase; first 
explanatory variable: substratum; second explanatory variable: locality) even though these results deserve some caution due to the low number of E. siliculosus gametophytes from Roscoff.

\section{Results}

\section{E. CROUANIORUM IN ROSCOFF, FRANCE: ALTERNATION BETWEEN MACROSCOPIC, EPIPHYTIC, HAPLOID GAMETOPHYTES AND MINUTE, EPILITHIC, DIPLOID SPOROPHYTES}

Although the Roscoff sampling sites were regularly visited during the first year of our study, macroscopic individuals resembling Ectocarpus were only observed from March to September. These individuals, which were up to $12 \mathrm{~cm}$ in length, were always found epiphytically on a variety of taxa (Table 1). Subsequent taxonomic classification revealed, however, that E. crouaniorum grew exclusively on the seasonal, brown alga Scytosiphon lomentaria. Moreover, sex locus markers indicated that 73 out of the 74 E. crouaniorum samples were haploid gametophytes.

As previous field surveys noted a number of minute Ectocarpus thalli -rarely attaining more than 10 $\mathrm{mm}$ in size - growing on small pebbles and empty shells (Peters et al. 2010b), these substrata were collected during different seasons in 2011 and 2012 in addition to the epiphytic samples taken during spring and summer (Table 1). Close examination with the naked eye only revealed minute Ectocarpus thalli ( $<10 \mathrm{~mm}$ in size) on these abiotic samples on a few occasions; however, macroscopic Ectocarpus individuals developed on nearly all abiotic samples after 1-2 months of culture in the laboratory. As observed in 2010, epiphytic E. crouaniorum thalli collected during 2011 and 2012 were always on S. lomentaria; likewise, most of these E. crouaniorum epiphytic samples were haploid gametophytes (93\%). In contrast, 161 out of the 165 E. crouaniorum epilithic samples amplified PCR products for both male and female sex locus markers, indicating that they were sporophytes.

Over the three years, $95 \%$ of the macroscopic, epiphytic samples of E. crouaniorum were gametophytes whereas $98 \%$ of the minute, epilithic samples were sporophytes (Fig. 2). Moreover, 
gametophytes were only present in spring and summer when their host S. lomentaria also occurred, while sporophytes were found year-round (Fig. S2).

Among the 13 microsatellite markers initially used, five loci showed poor amplification from $E$. crouaniorum DNA (Table S1) and one additional locus was suspected to include null alleles (Table S2). Nonetheless, analyses of the remaining seven loci were highly congruent with the above results. First, microsatellite data supported estimates of ploidy level obtained from sex locus markers: gametophytes never showed heterozygous loci while all sporophytes displayed at least one heterozygous locus (Fig. S3). Second, in agreement with the presence of both haploid gametophytes and diploid sporophytes and the occurrence of a sexual life cycle, the degree of clonality was low. In fact, the number of distinct multilocus genotypes was close to the total number of individuals in both phases regardless of the period considered ( $R$ values for haploids and diploids ranging between $0.87-$ 1.00 and 0.94-0.96 respectively, Table 2). Also, except for a low number of locus pairings, linkage disequilibrium was minimal, as indicated by a low and non-significant association index $\bar{r}_{\mathrm{d}}\left(-0.010<\bar{r}_{\mathrm{d}}\right.$ $<0.028$, Table 2). The tests carried out in GenClone 2.0 indicated that these seven microsatellite markers were enough to resolve the genotypic diversity within both the haploid and the diploid $E$. crouaniorum datasets: (i) an asymptote was reached when the number of distinct multilocus genotypes was plotted against the number of all possible combinations of loci (Fig. S4), and (ii) the few multilocus genotypes occurring more than once exhibited low probabilities of arising through sexual reproduction (i.e., $\mathrm{P}_{\mathrm{sex}}<0.05 ;$ Table S3). Supporting these results, the addition of three supplementary loci did not substantially change the $R$ values of clonal diversity obtained from the first microsatellite set (Table 2).

\section{E. SILICULOSUS IN NAPLES, ITALY: A LIFE CYCLE SIMILAR TO THAT OF E. CROUANIORUM IN ROSCOFF, FRANCE}

A total of 198 E. siliculosus samples were collected in Naples in March 2012 (Table 1). The nearabsence of natural hard substratum at this locality limited the collection of epilithic samples and, 
consequently, a large percentage of these E. siliculosus (86\%) corresponded to epiphytic individuals. As observed for E. crouaniorum in Roscoff, all epiphytic samples were found growing on the host $S$. lomentaria and they were clearly visible to the naked eye $(2-10 \mathrm{~cm}$ in length) whereas for the epilithic samples only a small algal turf $(<1 \mathrm{~cm}$ in height) was perceivable at the time of collection. Also, sex locus markers indicated that epiphytic samples mainly corresponded to haploid gametophytes (152 samples, $89 \%$ ) while $75 \%$ of the minute, epilithic samples were diploid sporophytes (Fig. 2). However, the E. siliculosus gametophytes from Naples tended to be less restricted to the epiphytic niche than the E. crouaniorum gametophytes from Roscoff (Fig. 2, Table 3, GLM significant interaction).

Nine out of the 13 microsatellite markers showed successful amplification from E. siliculosus DNA (Table S1). Since inspection of the haploid samples did not indicate the presence of null alleles at any of these loci, they were all retained for further analysis (Table S2). As observed for the $E$. crouaniorum dataset in NW France, no inconsistency was found between sample ploidy inferred from the sex locus markers and zygosity inferred from microsatellite alleles (Fig. S3). However, and despite finding both haploid gametophytic and diploid sporophytic E. siliculosus samples, a certain degree of clonality was revealed by the analysis of the nine microsatellites. First, an important number of haploid individuals and, to a lesser extent, diploid individuals shared the same multilocus genotype, rendering estimates of clonal diversity relatively low $(R=0.56$ and 0.70 for haploids and diploids respectively, Table 2 ). Second, nearly $25 \%$ of the locus pairings revealed significant linkage disequilibrium and the association index $\bar{r}_{\mathrm{d}}$ showed low but significant values (Table 2). Moreover, even though the number of locus pairings indicating significant linkage disequilibrium was reduced by half in both datasets when repeated multilocus genotypes were removed, values of the association index $\bar{r}_{\mathrm{d}}$ remained significant.

The procedures implemented in the software GenClone suggested a lack of resolution of our microsatellite panel to determine the genotypic diversity of the haploid individuals. First, the 
relationship between the number of loci used and the genetic diversity revealed by them did not reach an asymptote (even though the increase was highly attenuated beyond six loci) indicating that the nine microsatellites employed were insufficient to identify all genetically unique individuals present among these samples (Fig. S4). Second, also denoting a possible overestimation of the clonality level of this population, the probability that two or more identical genotypes arose from sexual rather than asexual reproduction $\left(P_{\text {sex }}\right)$ frequently exceeded the 0.05 threshold (Table S3). Three new microsatellites were consequently amplified in the haploid samples sharing multilocus genotypes (Table S1), and sex was regarded as a fourth additional locus. Consistent with the indication that we had analysed an insufficient number of loci with our first microsatellite set, the estimate of clonal diversity changed considerably after increasing the number of loci (from 0.56 to 0.80 , Table 2). However, and despite GenClone 2.0 results showing both (i) an asymptote in the number of distinct multilocus genotypes with the nine loci (Fig. S4), and (ii) $P_{\text {sex }}$ values $<0.001$ (Table S3), a considerable increase in the estimate of clonal diversity was also observed in the diploid dataset after adding the same three supplementary loci (from 0.70 to 0.85 , Table 2 ).

\section{E. SILICULOSUS IN ROSCOFF, FRANCE: GAMETOPHYTES ARE NEARLY ABSENT AND REPRODUCTION IS MAINLY ASEXUAL}

E. siliculosus samples were also collected in Roscoff throughout our study. As in the case of $E$. crouaniorum, only epiphytic individuals were sampled in 2010 , but a considerable number of both epiphytic and epilithic E. siliculosus were obtained in 2011 and 2012 (Table 1). In agreement with the size observations mentioned above, epiphytic samples were noticeable at the time of collection whereas most epilithic individuals developed only after incubation of substratum in the laboratory. However, in contrast to what was found in E. crouaniorum and in the conspecific population of Naples, epiphytic E. siliculosus in Roscoff grew on a variety of host species (Fig. 2). Moreover, the DNA of nearly all these samples amplified both sex locus markers, indicating that they corresponded to diploid sporophytes (only 11 out of 156 E. siliculosus epiphytic samples, i.e., 7\%, amplified only the 
male or the female locus indicating that these samples corresponded to haploid gametophytes; Fig. 2, Fig. S2). The frequency of E. siliculosus gametophytes was even lower among the epilithic samples where all but one individual were diploid sporophytes (0.5\%; Fig. 2, Fig. S2). Comparing the Roscoff $E$. siliculosus life cycle to that of Naples E. siliculosus, it was clear that (i) there were many more gametophytes in Naples (Fig. 2, Table 4, GLM significant Locality Effect), (ii) the Roscoff gametophytes (when present) were mainly epiphytic (Fig. 2, Table 4, GLM significant Substratum Effect), and (iii) the epiphytic habit of gametophytes did not differ between the two localities (Fig. 2, Table 4, GLM no significant interaction).

As expected for samples that all correspond to the same species, E. siliculosus individuals from Roscoff consistently amplified the same nine microsatellite loci as the E. siliculosus individuals from Naples. In fact, $90.7 \%$ of the alleles found in Italy were also present in the French population. Microsatellite data not only corroborated the taxonomic identity of these samples but also their ploidy level: heterozygous loci were not observed in the $12 \mathrm{E}$. siliculosus samples identified as haploid gametophytes using sex locus markers but at least one heterozygous locus was found in all other individuals (Fig. S3). Reflecting the virtual absence of gametophytes and a mainly asexual life cycle, the number of repeated multilocus genotypes was relatively high in the diploid $E$. siliculosus samples from Roscoff, rendering clonal diversity estimates as low as 0.54 in 2010, 0.52 in 2011 and 0.70 in 2012 (Table 2). The occurrence of asexual reproduction in these samples was confirmed by a strong association between all (years 2011 and 2012) or nearly all (year 2010) locus pairings as well as by high and significant values of the association index $\bar{r}_{\mathrm{d}}$ (Table 2). Moreover, this strong association between loci was still evident after removing duplicate genotypes. In agreement with GenClone 2.0 results indicating that our initial panel of nine microsatellite markers sufficiently identified unique genotypes (Fig. S4, Table S3), clonality estimates only slightly increased upon the addition of three supplemental loci (Table 2).

\section{Discussion}


The Ectocarpus life cycle has long been studied under laboratory conditions leading to a conventional picture of an isomorphic, or slightly heteromorphic, haploid-diploid life cycle (but see Fritsch 1942a; Peters et al. 2010b). Our results reveal, however, a far more complex situation in natural populations highlighting the importance of studying life cycles within their evolutionary and ecological contexts

(Fig. 1). In the field, Ectocarpus exhibited a heteromorphic, haploid-diploid life cycle with gametophytes and sporophytes not only showing marked differences in size but also occupying different spatio-temporal niches (Fig. 3). In particular, gametophytes usually attained several $\mathrm{cm}$ in length, and were easily perceptible to the naked eye. Moreover, these gametophytes were found seasonally and almost exclusively epiphytically on the annual alga S. lomentaria, suggesting a quasiobligatory association. In contrast, sporophytes occurred all year round on abiotic substrata and, regardless of the sampling month, they rarely exceeded $1 \mathrm{~cm}$ in length; indeed, their presence was often uncovered only after incubating these abiotic substrata in the laboratory. Our study also identified a population deviating from the previous results as a consequence of a switch in the prevalent mode of reproduction. In the following section, we discuss whether the ecological differences evidenced in our study between haploid gametophytes and diploid sporophytes can account for the evolution and subsequent maintenance of both ploidy phases. Finally, we briefly consider which mechanisms might underlie the different reproductive mode observed for $E$. siliculosus in Roscoff.

\section{NICHE PARTITIONING BETWEEN GAMETOPHYTE AND SPOROPHYTE GENERATIONS: PROXIMATE}

\section{AND ULTIMATE EXPLANATIONS}

Our empirical data on haploid-diploid populations of Ectocarpus spp. apparently support the niche partitioning hypothesis. Concomitant with differences in size, haploid and diploid individuals of both E. crouaniorum and E. siliculosus exhibited different spatio-temporal distributions. Haploid-diploid life cycles where the two ploidy phases exhibit different spatio-temporal distributions should prevent competitive exclusion of one phase by the other and, as explained below, might also represent a 
highly adaptive strategy in the intertidal seascape, a habitat that varies considerably in both space and time. The size differences between haploid and diploid Ectocarpus appear correlated with two contrasting patterns of growth habit extensively reported for other filamentous seaweeds (Fritsch 1942b). According to this, and as we could repeatedly observe during our field samplings, haploid individuals would grow mainly as upright, discrete filaments. In contrast, diploid individuals would develop as intertwined matrices of creeping filaments with much shorter upright branches (i.e., turflike growth). Available data on the early development of Ectocarpus sp. are consistent with these differences in growth pattern (Peters et al. 2008): the division of the initial cell in diploid sporophytes leads first to the establishment of a prostrate system, whereas an upright filament develops directly in haploid gametophytes. The functions of these two growth habits have been widely discussed in the literature and experimental work indicates that, while turf configurations are less productive than discrete individuals, they are more resistant to environmental stress (e.g. Hay 1981; Taylor and Hay, 1984). The haploid-diploid life cycle of Ectocarpus could thus be interpreted as an adaptation to a seasonally variable environment. Diploid individuals may withstand harsh conditions growing mainly as prostrate filaments in substratum crevices whereas haploid individuals may take advantage of benign spring conditions to grow rapidly over the canopy (i.e., as epiphytes) and reproduce. Indeed, this argument is very similar to that advanced by several authors to explain the evolution of heteromorphic haploid-diploid life cycles in many seaweeds that alternate between crustose and foliose phases (e.g. Lubchenco and Cubit 1980; Slocum 1980; Littler and Littler 1983; Zupan and West 1990; Cunningham et al. 1993; Edwards 2000).

Paradoxically, it seems unlikely that the obvious ecological advantage described above constitute the ultimate explanation for the evolution of haplo-diploidy in Ectocarpus. Our study shows that, under mild laboratory conditions, minute diploid sporophytes of both species grow as large as haploid gametophytes. Additional work would be needed to verify whether the opposite also occurs (e.g., by cultivating the haploid gametophytes under suboptimal conditions or by performing reciprocal transplants in the field), but this observation strongly suggests that the morphological differences 
between haploid and diploid Ectocarpus are a plastic response to the environment rather than a direct consequence of ploidy. The absence of an obligate relationship between morphology and ploidy is not atypical among haploid-diploid seaweeds. Even in species exhibiting strongly heteromorphic life cycles, it is known that the alternation of their morphological generations can proceed without alternation of cytological phases (Feldmann 1972). Indeed, two lines of evidence indicate that a similar detachment is possible in Ectocarpus sp. First, an apomictic life cycle by which unfused gametes give rise to morpho-functional sporophytes has been repeatedly recorded (Müller 1967; Bothwell et al. 2010) and, at least under laboratory conditions, seems a common phenomenon. Second, the description of several life cycle mutants also demonstrates that life cycle progression can be uncoupled from ploidy (Peters et al. 2008; Coelho et al. 2011). Taken together, these data lead us to think that morphological differences and the potential ecological advantages they provide probably arose as a secondary adaptation in an organism that already had a haploiddiploid life cycle. Consequently, the niche partitioning hypothesis could account for the maintenance of haplo-diploidy in these Ectocarpus spp. populations over evolutionary time but it does not seem to provide a plausible explanation for its initial evolution.

The previous partial validation of the niche partitioning hypothesis is however somewhat controversial when we consider the results from our third, mainly-asexual population. Despite consisting almost exclusively of diploid sporophytes, this E. siliculosus population in NW France exhibited an ecological differentiation comparable to that described for haploid-diploid populations. In fact, in agreement with the morphological plasticity postulated above, diploid individuals were not only found both epiphytically and epilithically but also displayed morphologies consistent with their habitats (i.e., "creeping" when epilithic and "upright" when epiphytic). At first glance, and as predicted by the niche partitioning hypothesis, it appeared that diploid sporophytes had outcompeted haploid gametophytes in this population. However, the epiphytic individuals of this population grew on a variety of taxa and not only on S. lomentaria as expected under a scenario of competitive exclusion. The interpretation of these findings and, in particular, the comparison with 
haploid-diploid populations is not straightforward. First, since the alternation of ploidy phases is tightly linked to sexual reproduction, haploid and diploid individuals in this population might be no longer interacting. Second, as explained in the next section, the history and evolutionary forces acting on this population are largely unknown. Still, the fact that a single ploidy phase exploits the environment as efficiently as the two ploidy phases together brings into question the presumed ecological advantage of haploid-diploid life cycles.

An alternative explanation to the niche partitioning hypothesis, based on the reproductive features of each ploidy phase rather than on their ecological differences, could not only reconcile our results from sexual and asexual populations but also account for the initial evolution of haploid-diploid life cycles. According to this explanation, the differential fate of the reproductive propagules of the two ploidy phases may have led to the emergence of two complementary reproductive strategies. In particular, diploid individuals may maximize dispersal given that their spores can germinate immediately after their release; conversely, haploid individuals may maximize fertilization as their gametes must fuse before germination (Bower 1908, Bell 1997). This hypothesis, albeit speculative, is consistent with several aspects of the Ectocarpus life cycle revealed by our study. First of all, it is important to note that Ectocarpus spp. is a sessile broadcast spawner (i.e., both male and female gametes are released to the surrounding environment and fertilization occurs externally) and, therefore, important trade-offs exist between successful fertilization and dispersal. Second, recruitment of Ectocarpus gametophytes on a single, ephemeral host species likely reduces the spatio-temporal environment in which fertilization occurs and enhances gamete fusion. Indeed, the strict pattern of ecological specialization observed between the gametophytes of Ectocarpus and $S$. lomentaria represents a substantial deterrent to the validation of the niche partitioning hypothesis (especially when in both Roscoff and Naples other potentially suitable hosts were available but were not exploited). Third, in agreement with higher gamete fusion rates postulated above for gametophytes occupying a very narrow spatio-temporal niche, parthenosporophytes were not detected among our field samples (as evidenced by the absence of epilithic, haploid individuals 
sharing the same multilocus genotype; Fig. 1) despite the prevalence of this phenomenon under laboratory conditions. Unfortunately, the destructive sampling of our work made a parent pair analysis impossible but we predict that diploid sporophytes often arise from gametophytes cohabiting the same S. lomentaria thallus. Finally, the fact that Ectocarpus sporophytes grow on a variety of substrata and under a wide range of environmental conditions agrees with their putative dispersal role. Indeed, clear evidence of such a generalist habit can be found in the frequent reports of Ectocarpus as a major ship-fouling organism (Russell and Morris 1970; Baker and Evans 1973; Morris and Russell 1974).

Previous discussions linking the stability of haploid-diploid life cycles to fertilization and dispersal have been based on morphological characteristics. In particular, Bell (1997) proposed that evolution might favour short gametophytes (allowing gametes to be released into the low-velocity environment near the substratum), but tall sporophytes (allowing spores to be released into the high-velocity environment of the water column). The hypothesis presented here integrates additional parameters such as spatio-temporal considerations, allowing the debate to be extended to other haploid-diploid species regardless of their morphologies. Indeed, although it has been suggested that the size tendency mentioned above agrees in general terms with the evolutionary characteristics of the brown algae (i.e., sporophyte size increases from ancestral to more recently diverged lineages; Bell 1997), currently accepted phylogenies provide a quite different picture and indicate that morphological features alone cannot support the underlying explanation (Cock et al. 2014). To the best of our knowledge, there has not been any other attempt to link the stability of haploid-diploid life cycles to fertilization and dispersal apart from the previous comparative work on brown algae. More studies are certainly needed but, since the hypothesis postulated in this work relies on the most intrinsic feature of haploids and diploids (apart from their chromosome set number), it is reasonable to think that it may be relevant to other haploid-diploid groups. 
Only a small number of $E$. siliculosus gametophytes were found in Roscoff during three consecutive years, and a considerable number of the sporophytes isolated shared the same multilocus genotype. These results suggest that this species was mainly reproducing asexually at this locality. In addition, we were unable to induce Roscoff $E$. siliculosus sporophytes to produce unilocular sporangia in the laboratory, even though the same protocol (Müller 1963) was successful for the conspecific population of Naples as well as for E. crouaniorum (L. Couceiro, unpublished data). Taken together, these observations suggest a loss of sexual fertility in this population and raise the question of possible evolution towards an asexual life cycle. We do not understand at present why this population reproduces asexually, especially as the conspecific population in Naples was sexual, but presumably this behaviour is related to the specific conditions that occur at Roscoff.

E. siliculosus gametophytes exhibited considerable preference for $S$. lomentaria as a host species, in both Roscoff and Naples (eight out of the 12 gametophytes found in Roscoff were growing on $S$. lomentaria and epiphytic gametophytes in Naples were only found on this species). E. crouaniorum gametophytes also grew on S. lomentaria in Roscoff and it is therefore possible that competition between the gametophytes of E. crouaniorum and E. siliculosus occurs in this locality. Indeed, most of the few E. siliculosus gametophytes collected at this locality were sampled between June and September, after the peak abundance of E. crouaniorum gametophytes, which occurs between March and June. However, it is worth mentioning that E. siliculosus populations reproducing asexually or predominantly asexually have been reported at other localities in Northern Europe (see Müller 1977 and references therein) and, therefore, the asexuality of the studied population in NW France could correspond to a more general pattern.

\section{CONCLUDING REMARKS AND PERSPECTIVES}

Our study opens new and interesting perspectives in the evolution of haploid-diploid life cycles in general and the Ectocarpus life cycle in particular. Conforming to theoretical predictions, haploid and diploid Ectocarpus exhibited clear niche partitioning. However, an ecological interpretation of these 
niche differences poses certain difficulties and, notably, indicates that the same advantage can be attained in the absence of alternation of ploidy phases. Moreover, this ecological interpretation simply does not explain the non-random association between Ectocarpus gametophytes and $S$. lomentaria. These findings may instead support the hypothesis of contrasting reproductive roles of gametophytes and sporophytes (i.e., fertilization vs dispersal) but, for the first time, incorporate spatio-temporal considerations. Ectocarpus-Scytosiphon represents a very interesting system for coevolutionary studies since Ectocarpus sporophytes are subject to evolutionary pressures that may differ from those that act on the gametophyte host S. lomentaria. Also, the study of horizontal transmission between the epilithic and the epiphytic niches may provide valuable insights into recognition mechanisms that mediate host specificity in algae. Finally, the differences we observed regarding the prevalent mode of reproduction of different Ectocarpus populations provide a good opportunity to investigate the advantages/drawbacks of different reproductive strategies under particular ecological constraints. Undoubtedly, the broad array of genetic and genomic tools available for this taxon will be of great value in addressing these topics.

\section{Acknowledgments}

Funding for this work was provided by the Agence Nationale de la Recherche (projects Bi-Cycle, ANR10-BLAN-1727; Sexseaweed, ANR12-JSV7-0008; and Clonix, ANR11-BSV7-00704), the University Pierre and Marie Curie (Emergence program), the Interreg program France (Channel) - England (project Marinexus), the EU FP7 “capacities" specific program ASSEMBLE (grant no. 227799), and the National Science Foundation's International Research Experiences for Students program (grant no. OISE-0652093). The authors thank Biogenouest Core Facility for its technical assistance and the members of the Stazione Zoologica di Napoli for their advice and logistic support during sampling in Italy. The authors are most grateful to the editors and two anonymous reviewers for their constructive comments. The authors declare no conflicts of interest. 
TABLE 1. Sampling sites characteristics (geographic coordinates; height expressed both as meters above mean sea level, AMSL, and meters over the year (2010/2011/2012).

\begin{tabular}{|c|c|c|c|c|c|c|c|c|c|c|}
\hline \multirow[b]{2}{*}{ Site } & \multicolumn{2}{|c|}{ Coordinates (WGS 84) } & \multicolumn{2}{|c|}{ Height (m) } & \multirow[b]{2}{*}{ Exposure } & \multirow[b]{2}{*}{ Comment } & \multicolumn{2}{|c|}{ No. epiphytic } & \multicolumn{2}{|c|}{ No. epilithic } \\
\hline & Latitude & Longitude & AMSL & Over lowest site & & & Ecro & Esil & Ecro & Esil \\
\hline Roscoff \#1 & 48.7209 & -4.0125 & 0.083 & 3.90 & Sheltered & Run-off in upper intertidal & $37 / 48 / 43$ & $1 / 1 / 0$ & $--/ 37 / 64$ & $--/ 2 / 10$ \\
\hline Roscoff \#2 & 48.7239 & -4.0130 & No data & $\sim 3.50$ & Sheltered & Tide-pool in mid intertidal & $0 / 0 / 25$ & $4 / 0 / 14$ & $--/ 0 / 0$ & $--/ 0 / 0$ \\
\hline Roscoff \#3 & 48.7233 & -4.0145 & -0.711 & 3.10 & Sheltered & Run-off in mid intertidal & $0 / 3 / 0$ & $40 / 14 / 34$ & $--/ 16 / 5$ & $--/ 23 / 18$ \\
\hline Roscoff \#4 & 48.7227 & -4.0169 & -1.517 & 2.30 & Sheltered & Run-off in mid intertidal & $37 / 1 / 0$ & $1 / 8 / 0$ & $--/ 31 / 4$ & $--/ 18 / 11$ \\
\hline Roscoff \#5 & 48.7229 & -4.0200 & -2.975 & 0.84 & Sheltered & Lower intertidal & $0 / 0 / 0$ & $8 / 4 / 0$ & $--/ 4 / 1$ & $--/ 38 / 22$ \\
\hline Roscoff \#6 & 48.7258 & -4.0175 & -2.361 & 1.45 & Sheltered & Lower intertidal & $0 / 0 / 0$ & $0 / 0 / 1$ & $--/ 0 / 1$ & $--/ 1 / 6$ \\
\hline Roscoff \#7 & 48.7252 & -4.0195 & -2.584 & 1.23 & Mid exposed & Lower intertidal & $0 / 0 / 0$ & $1 / 0 / 0$ & $--/ 0 / 0$ & $--/ 1 / 20$ \\
\hline Roscoff \#8 & 48.7261 & -4.0212 & -3.815 & 0.00 & Mid exposed & Edge of subtidal & $0 / 0 / 0$ & $0 / 0 / 0$ & $--/ 0 / 0$ & $--/ 0 / 2$ \\
\hline Roscoff \#9 & 48.7257 & -4.0247 & -3.018 & 0.80 & Exposed & Lower intertidal & $0 / 0 / 0$ & $0 / 0 / 0$ & $--/ 0 / 0$ & $--/ 0 / 0$ \\
\hline
\end{tabular}


Roscoff \#10 $\quad 48.7307 \quad-4.0038$

$-2.900 \quad 0.90$

No data ---

Naples \#1-3 $40.8258 \quad 14.2214$

6

7

8

9 
TABLE 2. Summary of the analyses aimed at asexual reproduction. Clonal diversity estimated using the initial set of microsatellites $\left(R_{1}\right)$ and after addition of

three supplementary loci $\left(R_{2}\right)$, number of pairwise comparisons across loci showing significant linkage disequilibrium (LD), and association index $\left(\bar{r}_{\mathrm{d}}\right)$.

Whenever possible, values are given for each species, year, and ploidy phase; also, linkage disequilibrium measures are provided both considering (with rMLGs) and dismissing (without rMLGs) duplicate genotypes.

\begin{tabular}{|c|c|c|c|c|c|c|c|c|c|}
\hline \multirow[b]{2}{*}{ Species - Locality } & \multirow[b]{2}{*}{ Ploidy phase } & \multirow[b]{2}{*}{ Year } & \multirow[b]{2}{*}{$N$} & \multirow[b]{2}{*}{$R_{1}$} & \multirow[b]{2}{*}{$R_{2}$} & \multicolumn{2}{|c|}{ with rMLGs } & \multicolumn{2}{|c|}{ without rMLGs } \\
\hline & & & & & & LD & $\bar{r}_{\mathrm{d}}$ & LD & $\bar{r}_{\mathrm{d}}$ \\
\hline \multirow[t]{5}{*}{ E. crouaniorum - Roscoff } & Gametophytes & 2010 & 62 & 0.87 & 0.95 & $2 / 21$ & -0.003 & $2 / 21$ & -0.004 \\
\hline & & 2011 & 44 & 1.00 & 1.00 & $0 / 21$ & -0.010 & $0 / 21$ & -0.010 \\
\hline & & 2012 & 55 & 0.94 & 0.98 & $0 / 21$ & -0.003 & $0 / 21$ & -0.005 \\
\hline & Sporophytes & 2011 & 78 & 0.94 & 0.96 & $2 / 21$ & $0.022^{*}$ & $0 / 21$ & $0.028 * * *$ \\
\hline & & 2012 & 67 & 0.96 & 0.97 & $2 / 21$ & -0.002 & $0 / 21$ & 0.004 \\
\hline \multirow[t]{2}{*}{ E. siliculosus - Naples } & Gametophytes & 2012 & 143 & 0.56 & 0.80 & $8 / 36$ & $0.057 * * *$ & $4 / 36$ & $0.059 * *$ \\
\hline & Sporophytes & 2012 & 34 & 0.70 & 0.85 & $9 / 36$ & $0.056 * *$ & $3 / 36$ & $0.040 * * *$ \\
\hline \multirow[t]{3}{*}{ E. siliculosus - Roscoff } & Sporophytes & 2010 & 57 & 0.54 & 0.61 & $32 / 36$ & $0.234 * * *$ & $17 / 36$ & $0.170 * * *$ \\
\hline & & 2011 & 131 & 0.52 & 0.55 & $36 / 36$ & $0.236 * * *$ & $24 / 36$ & $0.117 * * *$ \\
\hline & & 2012 & 129 & 0.70 & 0.84 & $36 / 36$ & $0.209 * * *$ & $36 / 36$ & $0.178 * * *$ \\
\hline
\end{tabular}


TABLE 3. Generalized Linear Model (logistic regression) testing whether the two life cycle stages (gametophytes and sporophytes) in E. crouaniorum from Roscoff and E. siliculosus from Naples (Species-Locality effect) are evenly distributed on the two kinds of substrata (epiphytic or epilithic, Substratum effect).

\begin{tabular}{lccccc}
\hline Effect & DF & Deviance & Resid. DF & Resid. Deviance & $p$-value \\
\hline Species-Locality & 1 & 43.95 & 555 & 693.16 & $3.367 \mathrm{e}-11$ \\
Substratum & 1 & 401.61 & 554 & 291.55 & $<2.2 \mathrm{e}-16$ \\
Species-Locality x Substratum & 1 & 23.48 & 553 & 268.06 & $1.260 \mathrm{e}-06$ \\
\hline
\end{tabular}


TABLE 4. Generalized Linear Model (logistic regression) testing whether the life cycle stages (gametophytes and sporophytes) of E. siliculosus from Naples and Roscoff (Locality effect) are evenly distributed on the two kinds of substrata (epiphytic or epilithic, Substratum effect).

\begin{tabular}{lccccc}
\hline Effect & DF & Deviance & Resid. DF & Resid. Deviance & $p$-value \\
\hline Locality & 1 & 375.89 & 541 & 300.67 & $<2.2$ e-16 \\
Substratum & 1 & 51.04 & 540 & 249.63 & 9.07 e-13 \\
Locality x Substratum & 1 & 0.05 & 539 & 249.58 & 0.8233 \\
\hline
\end{tabular}


FIGURE 1. The Ectocarpus life cycle. The diploid sporophyte produces haploid spores through meiotic divisions in unilocular sporangia. After settling, these motile meio-spores develop as male and female gametophytes, which in turn produce motile gametes through mitosis in plurilocular gametangia. Gamete fusion gives rise to a diploid zygote, which develops as a sporophyte and completes the sexual life cycle. Early observations in the laboratory also revealed the possibility of circumventing this sexual cycle (i.e. asexual looping): first, diploid sporophytes also form plurilocular sporangia from which spores produced by mitosis are released and grow to become new, genetically-identical sporophytes (Knight 1930; Müller 1964); second, unfused gametes can develop parthenogenetically giving rise to a haploid but completely-functional sporophyte (i.e., a partheno-sporophyte; Müller 1967). The cycle as described in the laboratory is represented in grey and the main features realised in nature for each species/locality are highlighted in bold; dashed boxes indicate the ecological niches. Note that gametophytes are represented as erect filaments while sporophytes show a prostrate base; also, unilocular sporangia are denoted by undivided circles while plurilocular sporangia and gametangia are denoted by divided ovals. Abbreviations: SP, sporophyte; G, gametophyte; pSP, partheno-sporophyte; F!, gamete fusion; R!, meiotic division; P!, parthenogenesis. Adapted from Peters et al. (2008).

FIGURE 2. Relative frequency of haploid gametophytes and diploid sporophytes in epiphytic and epilithic samples. (A) E. crouaniorum in Roscoff, (B) E. siliculosus in Naples, (C) E. siliculosus in Roscoff. The host identity of the epiphytic samples is represented as an independent diagram (abbreviations: Slom, Scytosiphon lomentaria; Smut, Sargassum muticum; Cfil, Chorda filum; Helo, Himanthalia elongata; Ulv, Ulva sp.; Und, undetermined; Zmar, Zostera marina; Ctam, Cystoseira tamariscifolia; Gra, Gracilaria sp.; Fserr, Fucus serratus; Chy, Chylocladia sp.; and Crum, Ceramium rubrum).

FIGURE 3. Ecology of field haploid-diploid Ectocarpus. (A) Haploid gametophytes growing as upright filaments on a S. lomentaria thallus, (B) Diploid sporophytes growing as turfs on a rock outcrop 
58 (please, note that this image corresponds to one of the few occasions where diploid sporophytes

59 were observed under field conditions). 


\section{Supplementary material}

TABLE S1. Genetic tools used in the present study. (A) Molecular identification of Ectocarpus to the species level: target markers, primer sequences, and expected sizes for each species. (B) Microsatellite loci: gene location (intron/exon/no gene), repeat array, primer sequences, multiplex identity, allele size range, and number of alleles $\left(\mathrm{N}_{\mathrm{A}}\right)$; note that estimates for each species at the first 13 loci are based on the total number of individuals (311 E. crouaniorum and 501 E. siliculosus) while the 3 last loci were only amplified in those samples showing repeated multilocus genotypes (37 E. crouaniorum and 292 E. siliculosus).

TABLE S2. Null allele frequencies. Comparison of direct estimates of null allele frequencies inferred from haploid individuals and indirect estimates provided by the Micro-checker software from diploid individuals. (A) E. crouaniorum 2010-2012, (B) E. crouaniorum 2011, (C) E. crouaniorum 2012, (D) E. siliculosus - Naples. Abbreviations: M1, Oosterhout method; M2, Chakraborty method; M3, Brookfield 1 method; M4: Brookfield 2 method. Significant null allele frequencies from both direct and indirect estimates are highlighted in bold.

TABLE S3. Ectocarpus spp. clones. List of clones inferred from the initial set of microsatellites in (A) E. crouaniorum, (B) E. siliculosus - Roscoff, and (C) E. siliculosus - Naples. For each clone, its frequency as well as the probability of being observed in $N$ samples as a consequence of different sexual events, i.e., $P_{\text {sex }}$ as estimated by GenClone, is provided. Values highlighted in bold denote $P>0.05$.

FIGURE S1. Geographic position and detailed view of the main study locality in NW France, comprising ten different sites along the shoreline gradient, as well as the reference locality in Naples, Italy.

FIGURE S2. Temporal distribution of epiphytic and epilithic samples over the three years in Roscoff. (A) E. crouaniorum gametophytes, (B) E. crouaniorum sporophytes, (C) E. siliculosus gametophytes, and (D) E. siliculosus sporophytes. 
84 FIGURE S3. Distribution of the number of heterozygous microsatellite loci per individual. Zygosity

85 level of E. siliculosus and E. crouaniorum samples identified as gametophytes (i.e. haploids) and

86 sporophytes (i.e. diploids) using sex-linked markers; only individuals showing successful amplification

87 at seven or more loci were considered.

88 FIGURE S4. Discrimination power of the initial set of microsatellites. Number of multilocus

89 genotypes discriminated into each dataset (i.e. E. crouaniorum gametophytes, E. crouaniorum

90 sporophytes, E. siliculosus sporophytes from Roscoff, E. siliculosus gametophytes from Naples, and $E$.

91 siliculosus sporophytes from Naples) as a function of the number of loci combined. 
Agapow, P. M. and A. Burt. 2001. Indices of multilocus linkage disequilibrium. Mol Ecol Notes 1:101-

94 102.

Ahmed, S., J. M. Cock, E. Pessia, R. Luthringer, A. Cormier, M. Robuchon, L. Sterck, A. F. Peters, S.M. Dittami, E. Corre, M. Valero, J.-M. Aury, D. Roze, Y. Van de Peer, J. H. Bothwell, G. Marais, and S. M. Coelho. 2014. A haploid system of sex determination in the brown alga Ectocarpus sp. Curr Biol $24: 1945-1957$.

Arnaud-Haond, S. and K. Belkhir. 2007. GenClone: a computer program to analyse genotypic data, test for clonality and describe spatial clonal organization. Mol Ecol Notes 7:15-17.

Baker, J. R. J. and L. V. Evans. 1973. The ship fouling alga Ectocarpus. I. Ultrastructure and cytochemistry of plurilocular reproductive stages. Protoplasma 77:1-13.

Bell, G. 1997. The evolution of the life cycle of brown seaweeds. Biol J Linn Soc 60:21-38. Berthold, G. 1881. Die geschlechtliche Fortpflanzung der eigentlichen Phaeosporeen. Mitt Zool Stn Neapel 2:401-413.

Bothwell, J. H., D. Marie, A. F. Peters, J. M. Cock, and S. M. Coelho. 2010. Role of endoreduplication and apomeiosis during parthenogenetic reproduction in the model brown alga Ectocarpus. New Phytol 188:111-121.

Bower, F. O. 1908. The origin of a land flora: a theory based upon the facts of alternation. Macmillan, London.

Carney, L. T. and M. S. Edwards. 2006. Cryptic processes in the sea: a review of delayed development in the microscopic life stages of marine macroalgae. Algae 21:161-168.

Cock, J. M., S. M. Coelho, C. Brownlee, and A. R. Taylor. 2010a. Featured papers on "The Ectocarpus genome sequence" [Special issue]. New Phytol 188:1-302.

Cock, J. M., O. Godfroy, N. Macaisne, A. F. Peters, and S. M. Coelho. 2014. Evolution and regulation of complex life cycles: a brown algal perspective. Curr Opin Plant Biol 17:1-6. 

Brownlee, C. J. Carrano, B. Charrier, G. Y. Cho, S. M. Coelho, J. Collen, E. Corre, C. Da Silva, L. Delage, N. Delaroque, S. M. Dittami, S. Doulbeau, M. Elias, G. Farnham, C. M. M. Gachon, B. Gschloessl, S. Heesch, K. Jabbari, C. Jubin, H. Kawai, K. Kimura, B. Kloareg, F. C. Kupper, D. Lang, A. Le Bail, C. Leblanc, P. Lerouge, M. Lohr, P. J. Lopez, C. Martens, F. Maumus, G. Michel, D. Miranda-Saavedra, J.

Coelho, S. M., O. Godfroy, A. Arun, G. Le Corguillé, A. F. Peters, and J. M. Cock. 2011. OUROBOROS is a master regulator of the gametophyte to sporophyte life cycle transition in the brown alga Ectocarpus. Proc Natl Acad Sci Unit States Am 108:11518-11523.

Coelho, S. M., A. F. Peters, B. Charrier, D. Roze, C. Destombe, M. Valero, and J. M. Cock. 2007.

Complex life cycles of multicellular eukaryotes: New approaches based on the use of model organisms. Gene 406:152-170.

Coluccio, A. E., R. K. Rodriguez, M. J. Kernan, and A. M. Neiman. 2008. The yeast spore wall enables spores to survive passage through the digestive tract of Drosophila. PLoS One 3:e2873.

Crow, J. F. and M. Kimura. 1965. Evolution in sexual and asexual populations. Am Nat 99:439-450. development, life history and biogeography of Helminthora stackhousei (Rhodophyta) by daylength and temperature. J Exp Mar Biol Ecol 171:1-21. red alga, Gracilaria verrucosa? J Evol Biol 2:317-338. 
Dorken, M. E. and C. G. Eckert. 2001. Severely reduced sexual reproduction in northern populations

143 of a clonal plant, Decodon verticillatus (Lythraceae). J Ecol 89:339-350.

144 Edwards, M. S. 2000. The role of alternate life-history stages of a marine macroalga: A seed bank 145 analogue? Ecology 81:2404-2415.

146 Feldmann, J. 1972. Les problèmes actuels d l’alternance de générations chez les Algues. Bull Soc Bot 147 France 119:7-38.

148 Fierst, J., C. terHorst, J. E. Kübler, and S. Dudgeon. 2005. Fertilization success can drive patterns of 149 phase dominance in complex life histories. J Phycol 41:238-249.

150 Frada, M., I. Probert, M. J. Allen, W. H. Wilson, and C. de Vargas. 2008. The "Cheshire Cat" escape 151 strategy of the coccolithophore Emiliania huxleyi in response to viral infection. Proc Natl Acad Sci 152 Unit States Am 105:15944-15949.

153 Fritsch, F. E. 1942a. Studies in the comparative morphology of the algae II. The algal life-cycle. Ann 154 Bot 6:533-563.

155 Fritsch, F. E. 1942b. Studies in the comparative morphology of the algae I. Heterotrichy and juvenile stages. Ann Bot 6:397-412. Halkett, F., J.-C. Simon, and F. Balloux. 2005. Tackling the population genetics of clonal and partially clonal organisms. Trends Ecol Evol 20:194-201.

Hay, M. E. 1981. The functional morphology of turf-forming seaweeds: persistence in stressful marine habitats. Ecology 62:739-750. brown alga Ectocarpus siliculosus provides large-scale assembly of the genome sequence. New Phytol 188:42-51. 320. 
167

Immler, S. and S. P. Otto. 2014. The evolution of ploidy differences between sexes under antagonistic selection. Am Nat 183:96-107.

Jenkins, C. D. and M. Kirkpatrick. 1995. Deleterious mutation and the evolution of genetic life cycles. Evolution 49:512-520.

Klinger, T. 1993. The persistence of haplodiploidy in algae. Trends Ecol Evol 8:256-258.

Knight, M. 1930. XV.-Studies in the Ectocarpaceæ. II. The life-history and cytology of Ectocarpus siliculosus, Dillw. Trans R Soc Edinburgh 56:307-332.

Littler, M. M. and D. S. Littler. 1983. Heteromorphic life-history strategies in the brown alga Scytosiphon lomentaria (Lyngb.) Link. J Phycol 19:425-431.

Lotka, A. J. 1925. Elements of physical biology. Williams \& Wilkins, Baltimore.

Lubchenco, J. and J. Cubit. 1980. Heteromorphic life histories of certain marine algae as adaptations to variations in herbivory. Ecology 61:676-687.

Mable, B. K. and S. P. Otto. 1998. The evolution of life cycles with haploid and diploid phases. BioEssays 20:453-462.

Mauger, S., L. Couceiro, and M. Valero. 2012. A simple and cost-effective method to synthesize an internal size standard amenable to use with a 5-dye system. Prime Res Biotechnol 2:40-46.

Morris, O. P. and G. Russell. 1974. Inter-specific differences in responses to copper by natural populations of Ectocarpus. Br Phycol J 9:269-272.

Müller, D. G. 1963. Die Temperaturabhängigkeit der Sporangienbildung bei Ectocarpus siliculosus von verschiedenen Standorten. Pubblicazioni Della Stazione Zoologica di Napoli 33:310-314.

Müller, D. G. 1964. Life-cycle of Ectocarpus siliculosus from Naples, Italy. Nature 203:1402-1402.

Müller, D. G. 1967. Generationswechsel, Kernphasenwechsel und Sexualität der Braunalge Ectocarpus siliculosus im Kulturversuch. Planta 75:39-54.

Müller, D. G. 1976. Relative sexuality in Ectocarpus siliculosus. A scientific error. Arch Microbiol 109: 89-94. 
Müller, D. G. 1977. Sexual reproduction in British Ectocarpus siliculosus (Phaeophyta). Br Phycol J 12:131-136.

Orr, H. A. and S. P. Otto. 1994. Does diploidy increase the rate of adaptation? Genetics 136:14751480.

Otto, S. P. 1996. Mating systems and the evolutionary transition between haploidy and diploidy. Biol J Linn Soc 57:197-218.

Otto, S. P. and A. C. Gerstein. 2008. The evolution of haploidy and diploidy. Curr Biol 18:R1121R1124.

Otto, S. P. and D. B. Goldstein. 1992. Recombination and the evolution of diploidy. Genetics 131:745751.

Pacheco-Ruíz, I. and J. A. Zertuche-González. 1999. Population structure and reproduction of the carrageenophyte Chondracanthus pectinatus in the Gulf of California. Hydrobiologia 398/399:159165.

Papenfuss, G. F. 1933. Note on the life-cycle of Ectocarpus siliculosus Dillw. Science 77:390-391. Papenfuss, G. F. 1935. Alternation of generations in Ectocarpus siliculosus. Bot Gaz 96:421-446. Paquin, C. and J. Adams. 1983. Frequency of fixation of adaptive mutations is higher in evolving diploid than haploid yeast populations. Nature 302:495-500.

Peakall, R. and P. E. Smouse. 2006. GENALEX 6: genetic analysis in Excel. Population genetic software for teaching and research. Mol Ecol Notes 6:288-295.

Peters, A. F., L. Couceiro, K. Tsiamis, F. C. Küpper, and M. Valero. 2015. Barcoding of cryptic stages of marine brown algae isolated from incubated substratum reveals high diversity in Acinetosporaceae (Ectocarpales, Phaeophyceae). Cryptogam Algol 36:3-29.

Peters, A. F., A. D. Mann, C. A. Córdova, J. Brodie, J. A. Correa, D. C. Schroeder, and J. M. Cock. 2010a. Genetic diversity of Ectocarpus (Ectocarpales, Phaeophyceae) in Peru and northern Chile, the area of origin of the genome-sequenced strain. New Phytol 188:30-41. 
218 (Ectocarpales, Phaeophyceae) as a model organism for brown algal genetics and genomics. J Phycol 40:1079-1088.

Peters, A. F. and M. E. Ramírez. 2001. Molecular phylogeny of small brown algae, with special reference to the systematic position of Caepidium antarcticum (Adenocystaceae, Ectocarpales). Cryptogam Algol 22:187-200.

Peters, A. F., D. Scornet, M. Ratin, B. Charrier, A. Monnier, Y. Merrien, E. Corre, S. M. Coelho, and J.

M. Cock. 2008. Life-cycle-generation-specific developmental processes are modified in the immediate upright mutant of the brown alga Ectocarpus siliculosus. Development 135:1503-1512. Peters, A. F., S. J. Van Wijk, G. Y. Cho, D. Scornet, T. Hanyuda, H. Kawai, D. C. Schroeder, M. J. Cock, and S. M. Boo. 2010b. Reinstatement of Ectocarpus crouaniorum Thuret in Le Jolis as a third common species of Ectocarpus (Ectocarpales, Phaeophyceae) in Western Europe, and its phenology at Roscoff, Brittany. Phycol Res 58:157-170.

Polifrone, M., M. C. Gil-Rodríguez, S. Domínguez-Álvarez, M. Stroobant, and M. A. Viera-Rodríguez.

2012. Reproductive phenology of three species of Gelidiales (Rhodophyta) in two macroalgal communities from Tenerife (Atlantic Ocean, Canary Islands, Spain). Anales Jard Bot Madrid 69:247252.

Raymond, M. and F. Rousset. 1995. GENEPOP (Version 1.2): population genetics software for exact tests and ecumenicism. J Hered 86:248-249.

Rice, W. R. 1989. Analyzing tables of statistical tests. Evolution 43:223-225.

Russell, G. and O. P. Morris. 1970. Copper tolerance in the marine fouling alga Ectocarpus siliculosus.

Slocum, C. J. 1980. Differential susceptibility to grazers in two phases of an intertidal alga:

Advantages of heteromorphic generations. J Exp Mar Biol Ecol 46:99-110. 
242 Taylor, P. R. and M. E. Hay. 1984. Functional morphology of intertidal seaweeds: adaptive

243 significance of aggregate vs. Solitary forms. Mar Ecol Prog Ser 18:295-302.

244 Thornber, C. S. 2006. Functional properties of the isomorphic biphasic algal life cycle. Integr Comp 245 Biol 46:605-614.

246 Valero, M., S. Richerd, V. Perrot, and C. Destombe. 1992. Evolution of alternation of haploid and 247 diploid phases in life cycles. Trends Ecol Evol 7:25-29.

248 Van Oosterhout, C., W. F. Hutchinson, D. P. M. Wills, and P. Shipley. 2004. Micro-checker: software 249 for identifying and correcting genotyping errors in microsatellite data. Mol Ecol Notes 4:535-538.

250 Vergés, A., N. A. Paul, and P. D. Steinberg. 2008. Sex and life-history stage alter herbivore responses 251 to a chemically defended red alga. Ecology 89:1334-1343.

252 Volterra, V. 1926. Fluctuations in the abundance of a species considered mathematically. Nature $253 \quad 118: 558-560$.

254 Willson, M. F. 1981. On the evolution of complex life cycles in plants: A review and an ecological 255 perspective. Ann Mo Bot Gard 68:275-300.

256 Zupan, J. R. and J. A. West. 1990. Photosynthetic responses to light and temperature of the 257 heteromorphic marine alga Mastocarpus papillatus (Rhodophyta). J Phycol 26:232-239. 


\section{E. crouaniorum in Roscoff}

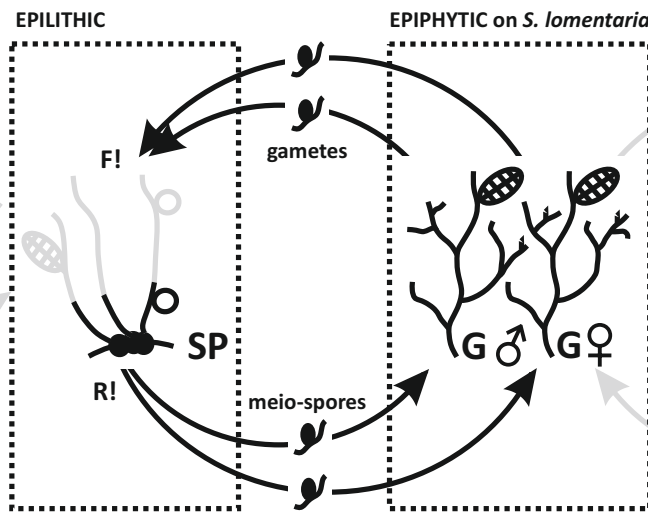

\section{E. siliculosus in Naples}

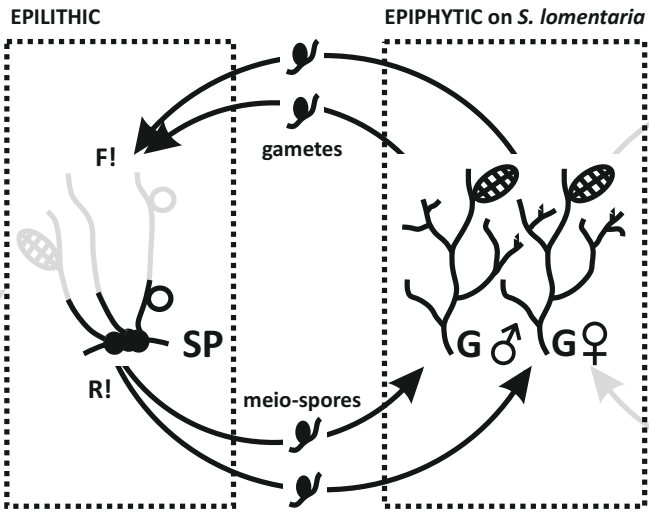

\section{E. siliculosus in Roscoff}
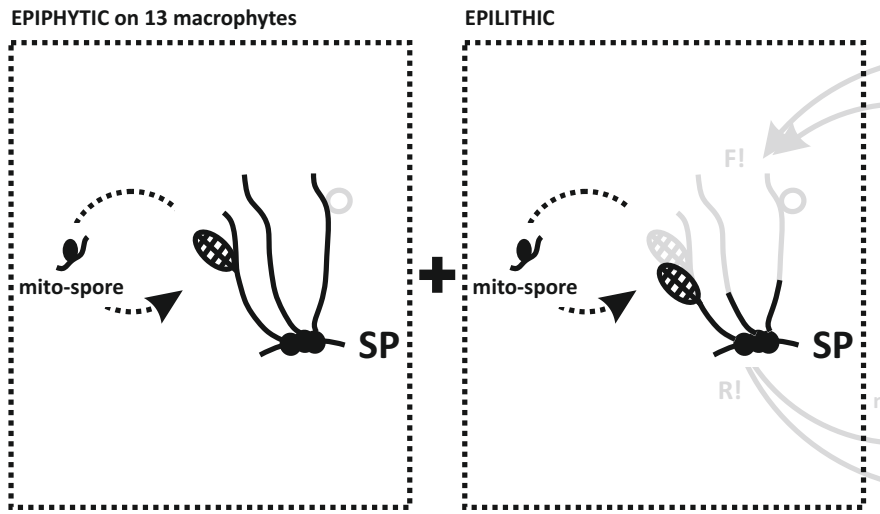

Figure 1 
A E. crouaniorum - Roscoff

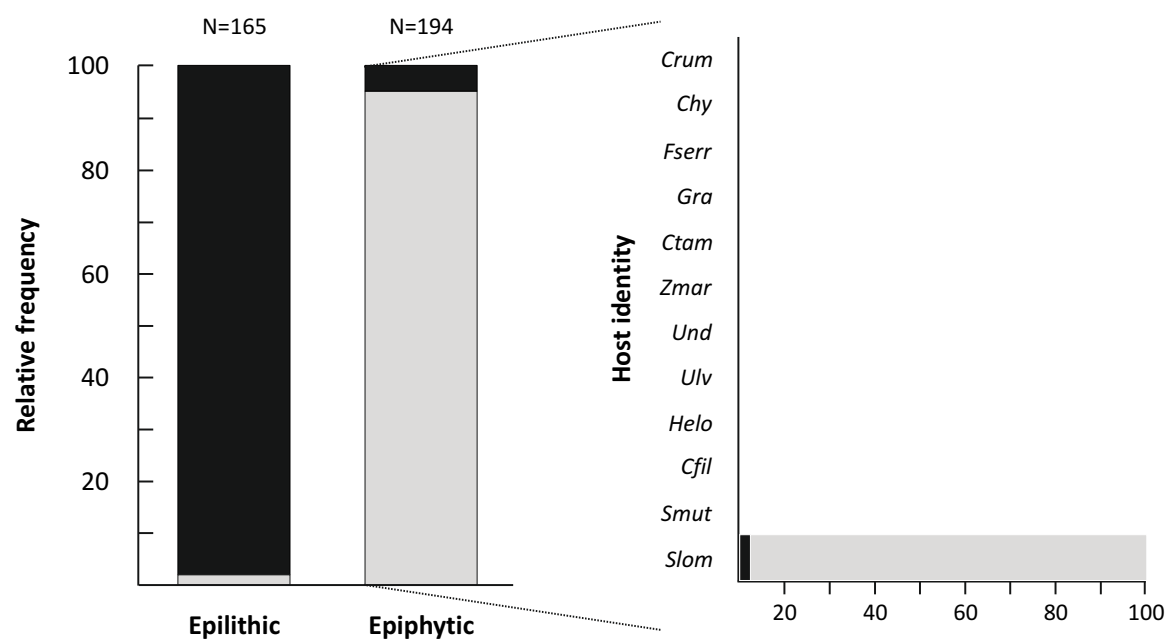

B E. siliculosus - Naples

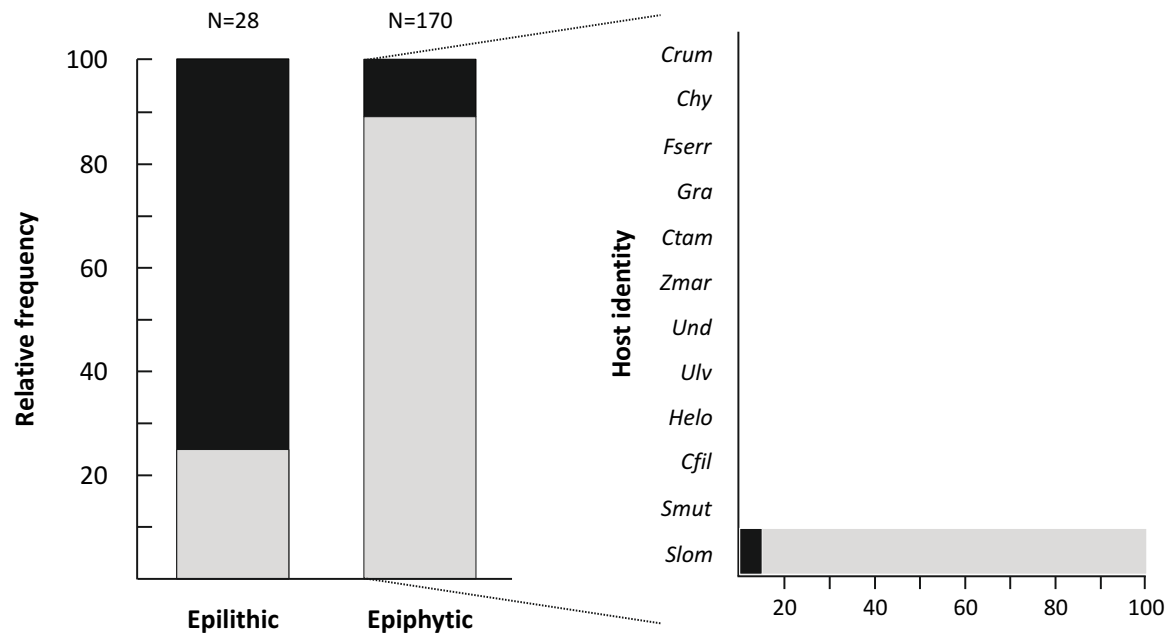

C E. siliculosus - Roscoff

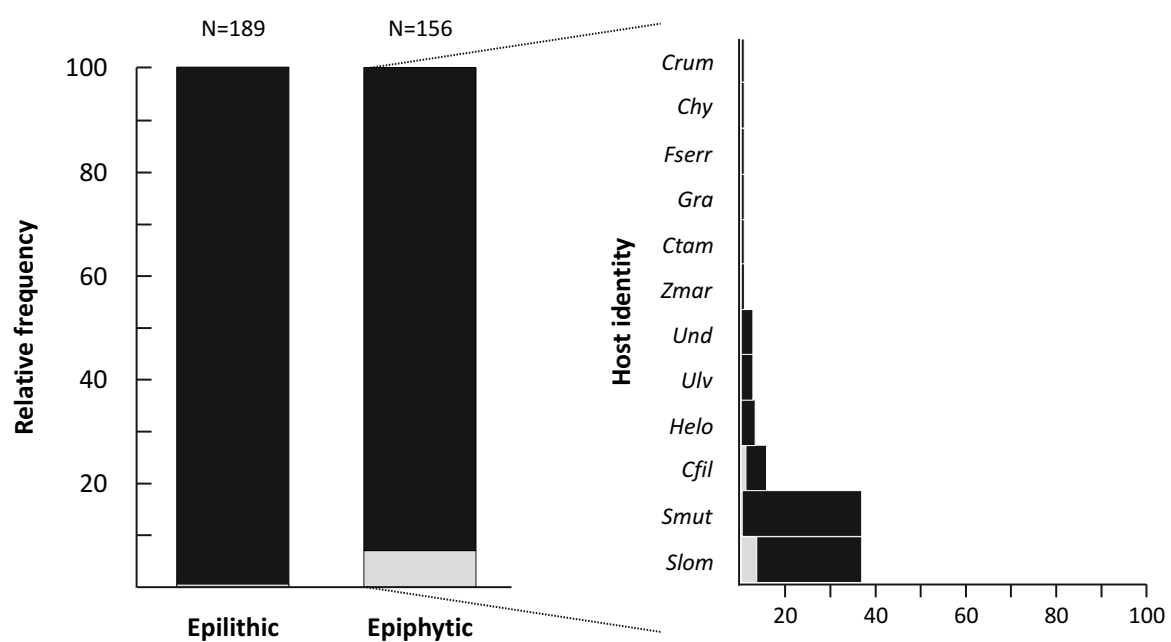

Sporophytes

Gametophytes

Figure 2 

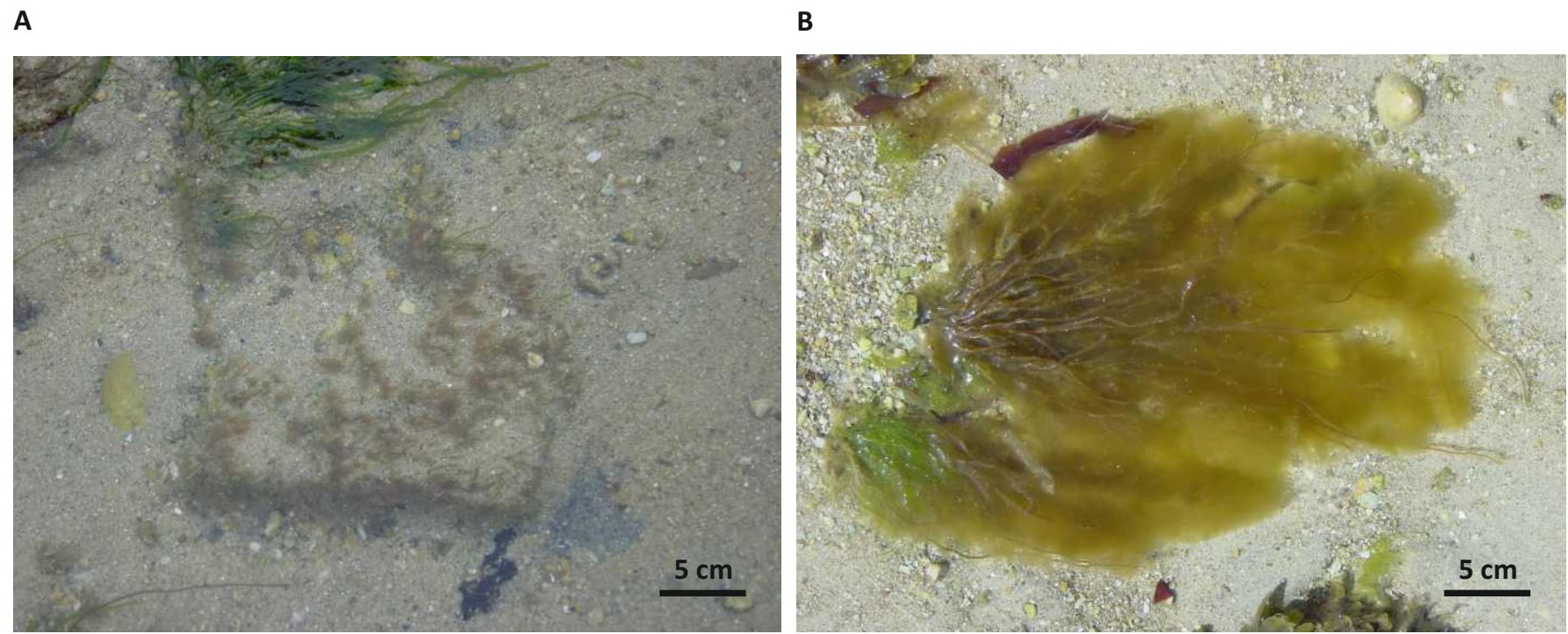

Figure 3 
Primer name: sequence $5^{\prime}-3^{\prime}$

Expected size (bp)

\begin{tabular}{|c|c|c|c|c|c|c|}
\hline Organelle & Marker & Forward & Reverse & Ecro & Esil & Efas \\
\hline Nucleus & ITS1 region ${ }^{(1)}$ & EcSSU1695_F: GAG GAT CTC GGA TTT TGT TG & 5.8S1_R: TGA TGA TTC ACT GGA TTC TG & 1100 & 850 & 650 \\
\hline Mitochondrion & rps14-atp8 spacer & EsNapM2F: GAT TAA TAA TTT ATC TAT TTT AGT C & trnS-R1: ATT GAT TTA GCA AAC CAA GGC & NA & 350 & NA \\
\hline Mitochondrion & rps14-atp8 spacer & nad3-F1D: GGT AGY YTA GAT TGG GAA TG & EcroM2R: GTT TAT CTA CTT AAA GAG ATC & 350 & NA & NA \\
\hline
\end{tabular}

Ecro: E. crouaniorum; Esil: E. siliculosus; Efas: E. fasciculatus; NA: no amplification. ${ }^{(1)}$ Includes the entire ITS1 and 224bp of flanking sequences (129bp from SSU, 95bp from 5.8S) which do not differ among the three species. 


\begin{tabular}{|c|c|c|c|c|c|c|c|c|}
\hline Locus Dye & Gene location & Repeat array & Primer sequence $5^{\prime}-3^{\prime}$ & Multiplex & \multicolumn{2}{|c|}{ Size range $(b p)$} & \multicolumn{2}{|c|}{$\mathrm{N}_{\mathrm{A}}$} \\
\hline $\mathrm{M}-122-2^{\mathrm{VIC}}$ & & & ATC TGT ATG TCT CCT CTC GG & & & & & \\
\hline $\mathrm{M}-197^{\mathrm{NED}}$ & Intron & $(\mathrm{GA})_{5 \ldots} \ldots(\mathrm{GA})_{4 \ldots}(\mathrm{GA})_{17}$ & AAG GTT GGT TGT GGA GGT & 2 & $122-125$ & NA & 2 & --- \\
\hline \multirow[t]{2}{*}{$M-383-1^{V I C}$} & Intron & $(\mathrm{AAC})_{25}$ & GGG TGA GAC AGT AGT AGC AGG & 2 & 184-193 & NA & 3 & --- \\
\hline & & & CTC GGA ACA GGA AGG TTT & & & & & \\
\hline$M-033-1^{\text {NED }}$ & Exon & $(A G)_{8} \ldots(A G)_{40}$ & TGA GAA TAC CCT TTC CTC TAC & 2 & NA & $279-333$ & --- & 25 \\
\hline M-239-3 6-FAM & & & CAT TGA ACG ACA AAT CCC & & & & & \\
\hline \multirow[t]{2}{*}{$\mathrm{M}-006-4^{\mathrm{PET}}$} & Intron & $(\mathrm{TC})_{37}$ & GTA GGG AGT GGG TTC CAG & 3 & NA & 296-340 & --- & 16 \\
\hline & & & GCG TCA AGC AGT GAA ATA A & & & & & \\
\hline$M-103-2^{\text {NED }}$ & Exon & $(\mathrm{AG})_{23 \ldots}(\mathrm{AG})_{3 \ldots} \ldots(\mathrm{AG})_{5}$ & ATC GTT TGT TCC ATT TGC T & 3 & NA & $243-275$ & --- & 16 \\
\hline
\end{tabular}




\begin{tabular}{|c|c|c|c|c|c|c|c|c|}
\hline & & & TTG TCT CCA ACC CTT TGA C & & & & & \\
\hline \multirow[t]{2}{*}{$\mathrm{M}-387^{\mathrm{VIC}}$} & Exon & $(G A)_{23}$ & CGT GGA AGA TAA GGT GCT G & 3 & NA & $246-272$ & --- & 11 \\
\hline & & & CTC AAG CCC AAT GCC AAA & & & & & \\
\hline \multirow[t]{2}{*}{$\mathrm{M}-388^{\mathrm{PET}}$} & No gene & $(A G)_{20}$ & AGG AAC GGA CGG AGT AGT AG & 4 & $135-199$ & NA & 22 & --- \\
\hline & & & AGA TGA CAC TTG GAT TGG AC & & & & & \\
\hline \multirow[t]{2}{*}{$M-208^{\text {PET }}$} & No gene & $(\mathrm{GCT})_{20}$ & ATC GTT GAG AGG AGG GAG & 4 & $261-285$ & $270-315$ & 7 & 13 \\
\hline & & & CTC GGA ATA AGA GTG AGA CC & & & & & \\
\hline \multirow[t]{2}{*}{$M-062-5^{N E D}$} & No gene & $(\mathrm{CT})_{6 \ldots} \ldots(\mathrm{CT})_{27}$ & CAT CTT CTC CAC CTT GGG & 4 & $156-226$ & $154-180$ & 14 & 10 \\
\hline & & & AGT ATG AGG AAC TCG GGA A & & & & & \\
\hline \multirow[t]{2}{*}{$\mathrm{M}-162-1^{\mathrm{VIC}}$} & Intron & $(G A)_{10 \ldots(G A)_{22}}$ & ACA CAC AAG GGA GAC GAA & 4 & $264-312$ & $282-350$ & 6 & 26 \\
\hline & & & GTG ACG GTG CTG ATA GTA GTG & & & & & \\
\hline \multirow[t]{2}{*}{$M-420^{6-F A M}$} & No gene & $(\mathrm{CT})_{31}$ & GAC ACC CTA CAA GGA ACA AA & 4 & $261-335$ & NA & 32 & --- \\
\hline & & & AGC GTA TTG GCA CAG AGG & & & & & \\
\hline \multirow[t]{2}{*}{$\mathrm{M}-002 \mathrm{VIC}$} & Intron & $(\mathrm{CT})_{46}$ & GCA CAC ACA CAC ACA CAT ACT & 5 & NA & $204-258$ & --- & 4 \\
\hline & & & CTA CGC CGA CCT GAT TTG & & & & & \\
\hline $\mathrm{M}-081^{\mathrm{NED}}$ & No gene & $(\mathrm{CT})_{22 \ldots} \ldots(\mathrm{TC})_{24}$ & CTG TCT CTC CGT CTC TCT GT & 6 & $210-212$ & $196-216$ & 2 & 5 \\
\hline
\end{tabular}


AAT GTC TCC ATA CCC AAT GA

M-392 $2^{\text {PET }} \quad$ Intron $\left.\quad(\mathrm{GTT})_{2} \ldots(\mathrm{GTT})_{2} \ldots(\mathrm{GTT})_{23 \ldots(\mathrm{GTT}}\right)_{8} \ldots(\mathrm{GTT})_{2}$

GTG TGC GTG CTG TTG

6

$285-288 \quad 249-264 \quad 2$

GAC TTA GAT TTC CGT GTC CTC

Ecro: E. crouaniorum; Esil: E. siliculosus; NA: no amplification 
A

\begin{tabular}{lccccc}
\hline & & \multicolumn{5}{c}{ Indirect estimates } \\
Locus & Direct estimates & $\mathrm{M} 1$ & $\mathrm{M} 2$ & $\mathrm{M} 3$ & $\mathrm{M} 4$ \\
& & & & & \\
\hline $\mathrm{M}-122-2$ & 0.0062 & 0.1730 & 0.2077 & 0.1549 & 0.2160 \\
$\mathrm{M}-197$ & 0.0000 & 0.1328 & 0.1656 & 0.0939 & 0.0939 \\
$\mathrm{M}-383-1$ & 0.0000 & 0.0150 & 0.0167 & 0.0084 & 0.0084 \\
$\mathrm{M}-388$ & 0.0124 & 0.0589 & 0.0633 & 0.0542 & 0.0886 \\
$\mathrm{M}-208$ & 0.0062 & 0.0082 & 0.0077 & 0.0058 & 0.0698 \\
$\mathrm{M}-062-5$ & $\mathbf{0 . 3 5 4 0}$ & $\mathbf{0 . 2 8 9 3}$ & $\mathbf{0 . 4 3 5 2}$ & $\mathbf{0 . 2 7 0 6}$ & $\mathbf{0 . 4 9 1 9}$ \\
$\mathrm{M}-162-1$ & 0.0000 & 0.0840 & 0.1174 & 0.0390 & 0.0390 \\
$\mathrm{M}-420$ & 0.0683 & 0.2230 & 0.2896 & 0.2175 & 0.2682 \\
\hline
\end{tabular}

B

\begin{tabular}{lccccc}
\hline & & \multicolumn{5}{c}{ Indirect estimates } \\
Locus & Direct estimates & $\mathrm{M} 1$ & $\mathrm{M} 2$ & $\mathrm{M} 3$ & $\mathrm{M} 4$ \\
& & & & & \\
\hline $\mathrm{M}-122-2$ & 0.0000 & 0.1713 & 0.2092 & 0.1563 & 0.1563 \\
$\mathrm{M}-197$ & 0.0000 & 0.1875 & 0.2580 & 0.1367 & 0.1367 \\
$\mathrm{M}-383-1$ & 0.0000 & -0.0143 & -0.0111 & -0.0050 & 0.0000 \\
$\mathrm{M}-388$ & 0.0000 & 0.0756 & 0.0827 & 0.0690 & 0.1268 \\
$\mathrm{M}-208$ & 0.0227 & 0.0526 & 0.0566 & 0.0397 & 0.1246 \\
$\mathrm{M}-062-5$ & $\mathbf{0 . 4 0 9 1}$ & $\mathbf{0 . 2 5 8 8}$ & $\mathbf{0 . 3 7 6 0}$ & $\mathbf{0 . 2 3 3 6}$ & $\mathbf{0 . 4 5 5 2}$ \\
$\mathrm{M}-162-1$ & 0.0000 & 0.0380 & 0.0464 & 0.0163 & 0.0163 \\
$\mathrm{M}-420$ & 0.0227 & 0.2539 & 0.3435 & 0.2461 & 0.3023 \\
\hline
\end{tabular}


C

\begin{tabular}{lccccc}
\hline & & \multicolumn{5}{c}{ Indirect estimates } \\
Locus & Direct estimates & M1 & M2 & M3 & M4 \\
\hline M-122-2 & 0.0182 & 0.1721 & 0.2000 & 0.1480 & 0.2732 \\
M-197 & 0.0000 & 0.0400 & 0.0427 & 0.0263 & 0.0263 \\
M-383-1 & 0.0000 & 0.0220 & 0.0230 & 0.0130 & 0.0130 \\
M-388 & 0.0000 & 0.0305 & 0.0325 & 0.0288 & 0.0288 \\
M-208 & 0.0000 & -0.0636 & -0.0575 & -0.0476 & 0.0000 \\
M-062-5 & 0.2727 & $\mathbf{0 . 3 1 2 2}$ & $\mathbf{0 . 4 7 7 1}$ & $\mathbf{0 . 2 9 4 3}$ & $\mathbf{0 . 5 2 1 0}$ \\
M-162-1 & 0.0000 & 0.1019 & 0.1526 & 0.0483 & 0.0483 \\
M-420 & 0.1091 & 0.1602 & 0.1919 & 0.1552 & 0.2050 \\
\hline
\end{tabular}

D

Indirect estimates

\begin{tabular}{lccccc} 
Locus & Direct estimates & $\mathrm{M} 1$ & $\mathrm{M} 2$ & $\mathrm{M} 3$ & $\mathrm{M} 4$ \\
\hline $\mathrm{M}-122-2$ & 0.0070 & 0.2363 & 0.6290 & 0.1362 & 0.1362 \\
$\mathrm{M}-033-1$ & 0.0769 & 0.0376 & 0.0623 & 0.0492 & 0.2683 \\
$\mathrm{M}-239-3$ & 0.0559 & 0.1131 & 0.1303 & 0.0972 & 0.0972 \\
$\mathrm{M}-006-4$ & 0.0140 & -0.0431 & -0.0334 & -0.0274 & 0.0739 \\
$\mathrm{M}-103-2$ & 0.0070 & -0.0636 & -0.0760 & -0.0580 & 0.0000 \\
$\mathrm{M}-387$ & 0.0000 & -0.1388 & -0.1108 & -0.0994 & 0.0000 \\
$\mathrm{M}-208$ & 0.0070 & 0.0787 & 0.0414 & 0.0196 & 0.1331 \\
$\mathrm{M}-062-5$ & 0.0000 & -0.0500 & -0.0250 & -0.0044 & 0.0000 \\
$\mathrm{M}-162-1$ & 0.0000 & -0.1058 & -0.0777 & -0.0547 & 0.0000 \\
\hline
\end{tabular}


A

\begin{tabular}{|c|c|c|c|}
\hline Ploidy phase / Year & Clone & Frequency & $P_{\text {sex }}$ \\
\hline \multirow[t]{6}{*}{ Gametophytes - 2010} & $\mathrm{GA}^{\prime} 10-01$ & 3 & 0.01162593 \\
\hline & $\mathrm{GA}^{\prime} 10-02$ & 2 & 0.05351267 \\
\hline & $\mathrm{GA}^{\prime} 10-03$ & 2 & 0.02224146 \\
\hline & $\mathrm{GA}^{\prime} 10-04$ & 2 & 0.00052284 \\
\hline & $\mathrm{GA}^{\prime} 10-05$ & 2 & 0.01895503 \\
\hline & $\mathrm{GA}^{\prime} 10-06$ & 2 & 0.00389016 \\
\hline \multirow[t]{3}{*}{ Gametophytes - 2012} & $\mathrm{GA}^{\prime} 12-01$ & 2 & 0.00245488 \\
\hline & $\mathrm{GA}^{\prime} 12-02$ & 2 & 0.01221553 \\
\hline & $\mathrm{GA}^{\prime} 12-03$ & 2 & 0.02085132 \\
\hline \multirow[t]{3}{*}{ Sporophytes - 2011} & $S P^{\prime} 11-01$ & 4 & 0.00000094 \\
\hline & SP'11-02 & 2 & 0.00001828 \\
\hline & $S P^{\prime} 11-03$ & 2 & 0.00020842 \\
\hline \multirow[t]{2}{*}{ Sporophytes - 2012} & $S P^{\prime} 12-01$ & 2 & 0.00000058 \\
\hline & SP'12-02 & 3 & 0.00000192 \\
\hline
\end{tabular}


B

\begin{tabular}{|c|c|c|c|}
\hline Ploidy phase / Year & Clone & Frequency & $P_{\text {sex }}$ \\
\hline \multirow[t]{13}{*}{ Sporophytes - 2010} & $S P^{\prime} 10-01$ & 3 & 0.00000030 \\
\hline & $S P^{\prime} 10-02$ & 2 & 0.00000145 \\
\hline & $S P^{\prime} 10-03$ & 2 & 0.00000001 \\
\hline & $S P^{\prime} 10-04$ & 3 & 0.00000001 \\
\hline & $S P^{\prime} 10-05$ & 2 & 0.00000025 \\
\hline & $S P^{\prime} 10-06$ & 2 & 0.00000011 \\
\hline & $S P^{\prime} 10-07$ & 3 & 0.00000089 \\
\hline & $S P^{\prime} 10-08$ & 5 & 0.00000001 \\
\hline & SP'10-09 & 2 & 0.00000041 \\
\hline & $S P^{\prime} 10-10$ & 9 & 0.00000482 \\
\hline & $S P^{\prime} 10-11$ & 2 & 0.00000023 \\
\hline & $S P^{\prime} 10-12$ & 2 & 0.00000000 \\
\hline & $S P^{\prime} 10-13$ & 2 & 0.00000000 \\
\hline \multirow[t]{10}{*}{ Sporophytes - 2011} & SP'11-01 & 2 & 0.00000000 \\
\hline & $S P^{\prime} 11-02$ & 5 & 0.00000004 \\
\hline & $S P^{\prime} 11-03$ & 2 & 0.00000000 \\
\hline & SP'11-04 & 8 & 0.00000000 \\
\hline & $S P^{\prime} 11-05$ & 5 & 0.00000001 \\
\hline & SP'11-06 & 3 & 0.00000201 \\
\hline & $S P^{\prime} 11-07$ & 2 & 0.00000029 \\
\hline & SP'11-08 & 2 & 0.00000002 \\
\hline & $S P^{\prime} 11-09$ & 3 & 0.00000003 \\
\hline & $S P^{\prime} 11-10$ & 12 & 0.00000008 \\
\hline
\end{tabular}




\begin{tabular}{|c|c|c|c|}
\hline & $S P^{\prime} 11-11$ & 3 & 0.00000013 \\
\hline & $S P^{\prime} 11-12$ & 8 & 0.00000000 \\
\hline & $S P^{\prime} 11-13$ & 2 & 0.00000001 \\
\hline & $S P^{\prime} 11-14$ & 11 & 0.00000000 \\
\hline & $S P^{\prime} 11-15$ & 2 & 0.00000000 \\
\hline & $S P^{\prime} 11-16$ & 5 & 0.00000000 \\
\hline & $S P^{\prime} 11-17$ & 2 & 0.00000000 \\
\hline & $S P^{\prime} 11-18$ & 2 & 0.00000000 \\
\hline & $S P^{\prime} 11-19$ & 3 & 0.00000000 \\
\hline \multirow[t]{16}{*}{ Sporophytes - 2012} & $S P^{\prime} 12-01$ & 3 & 0.00000002 \\
\hline & $S P^{\prime} 12-02$ & 2 & 0.00000000 \\
\hline & $S P^{\prime} 12-03$ & 7 & 0.00000001 \\
\hline & $S P^{\prime} 12-04$ & 3 & 0.00000804 \\
\hline & $S P^{\prime} 12-05$ & 3 & 0.00001851 \\
\hline & $S P^{\prime} 12-06$ & 3 & 0.00000018 \\
\hline & $S P^{\prime} 12-07$ & 2 & 0.00000005 \\
\hline & $S P^{\prime} 12-08$ & 3 & 0.00000004 \\
\hline & $S P^{\prime} 12-09$ & 2 & 0.00000000 \\
\hline & $S P^{\prime} 12-10$ & 2 & 0.00000000 \\
\hline & $S P^{\prime} 12-11$ & 7 & 0.00000548 \\
\hline & $S P^{\prime} 12-12$ & 6 & 0.00000049 \\
\hline & $S P^{\prime} 12-13$ & 2 & 0.00000000 \\
\hline & $S P^{\prime} 12-14$ & 5 & 0.00000000 \\
\hline & $S P^{\prime} 12-15$ & 3 & 0.0000000 \\
\hline & $S P^{\prime} 12-16$ & 2 & 0.0000000 \\
\hline
\end{tabular}


C

\begin{tabular}{|c|c|c|c|}
\hline Ploidy phase / Year & Clone & Frequency & $P_{\text {sex }}$ \\
\hline \multirow[t]{18}{*}{ Gametophytes - 2012} & $\mathrm{GA}^{\prime} 12-01$ & 4 & 0.83792096 \\
\hline & $\mathrm{GA}^{\prime} 12-02$ & 15 & 0.94016412 \\
\hline & $G^{\prime} 12-03$ & 2 & 0.84983951 \\
\hline & $\mathrm{GA}^{\prime} 12-04$ & 3 & 0.51141882 \\
\hline & $\mathrm{GA}^{\prime} 12-05$ & 3 & 0.83792096 \\
\hline & GA'12-06 & 12 & 0.94016412 \\
\hline & $\mathrm{GA}^{\prime} 12-07$ & 5 & 0.95810257 \\
\hline & $\mathrm{GA}^{\prime} 12-08$ & 2 & 0.06715365 \\
\hline & $\mathrm{GA}^{\prime} 12-10$ & 3 & 0.40683114 \\
\hline & GA'12-11 & 3 & 0.55338624 \\
\hline & $G^{\prime} 12-12$ & 2 & 0.80328269 \\
\hline & $\mathrm{GA}^{\prime} 12-13$ & 2 & 0.15102663 \\
\hline & $G^{\prime} 12-14$ & 3 & 0.81625086 \\
\hline & $G^{\prime} 12-15$ & 2 & 0.24620670 \\
\hline & $G^{\prime} 12-16$ & 8 & 0.95810257 \\
\hline & $\mathrm{GA}^{\prime} 12-17$ & 2 & 0.19395672 \\
\hline & $G^{\prime} 12-18$ & 4 & 0.81625086 \\
\hline & $\mathrm{GA}^{\prime} 12-19$ & 5 & 0.15680240 \\
\hline \multirow[t]{5}{*}{ Sporophytes - 2012} & $S P^{\prime} 12-01$ & 2 & 0.00014392 \\
\hline & $S P^{\prime} 12-02$ & 2 & 0.00021642 \\
\hline & $S P^{\prime} 12-03$ & 3 & 0.00004083 \\
\hline & $S P^{\prime} 12-04$ & 2 & 0.00141066 \\
\hline & $S P^{\prime} 12-05$ & 3 & 0.00054096 \\
\hline
\end{tabular}




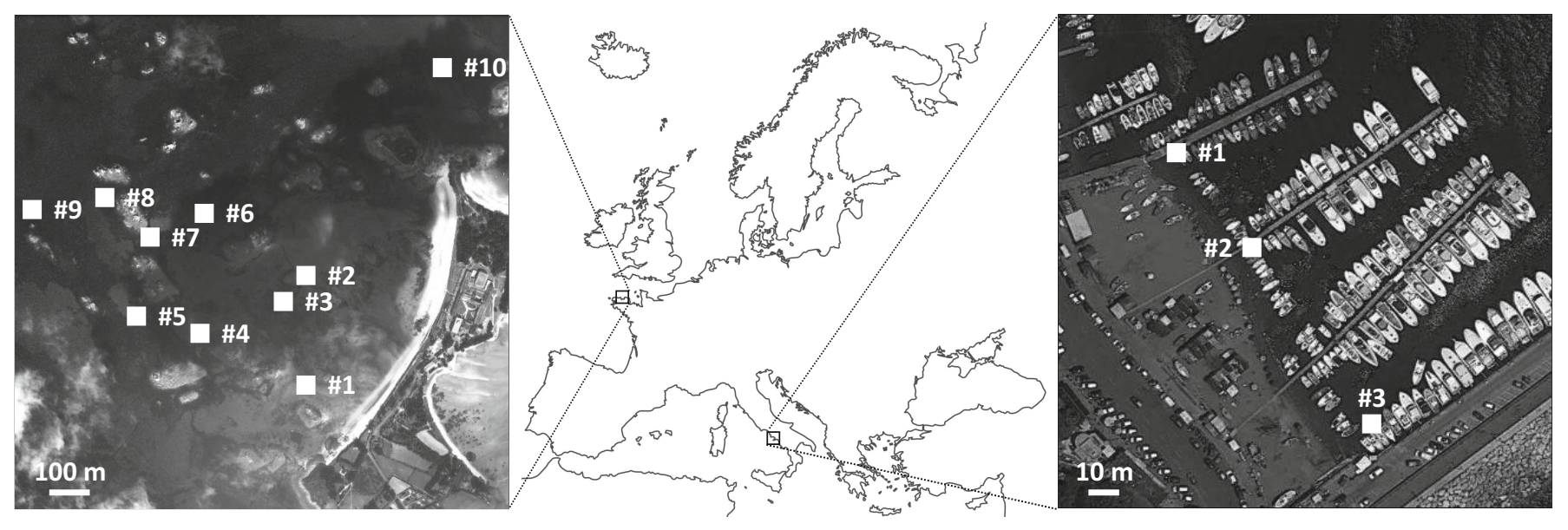




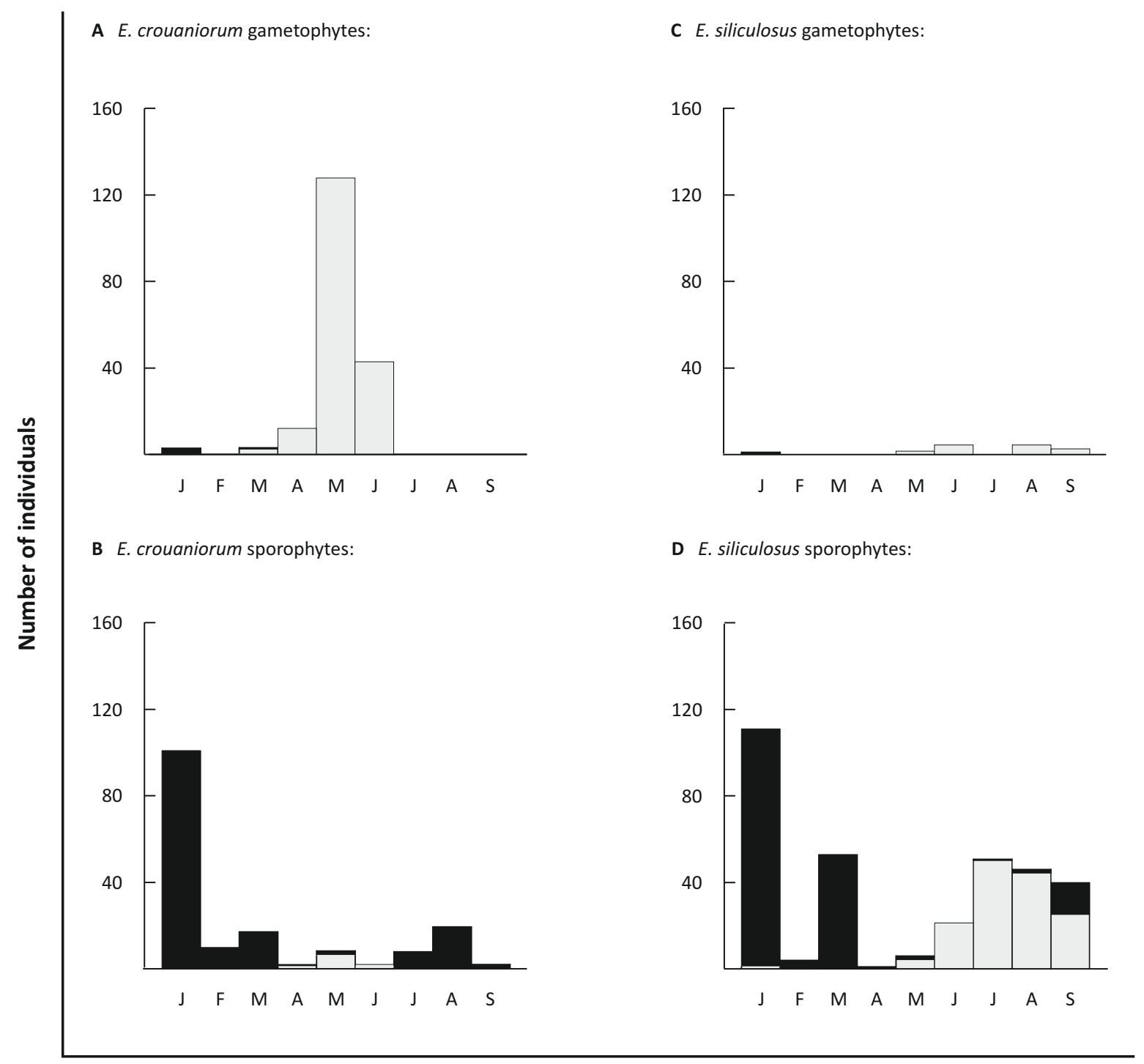

Month (from January to September)

$\square$ Epiphytic individuals $\square \quad$ Epilithic individuals 


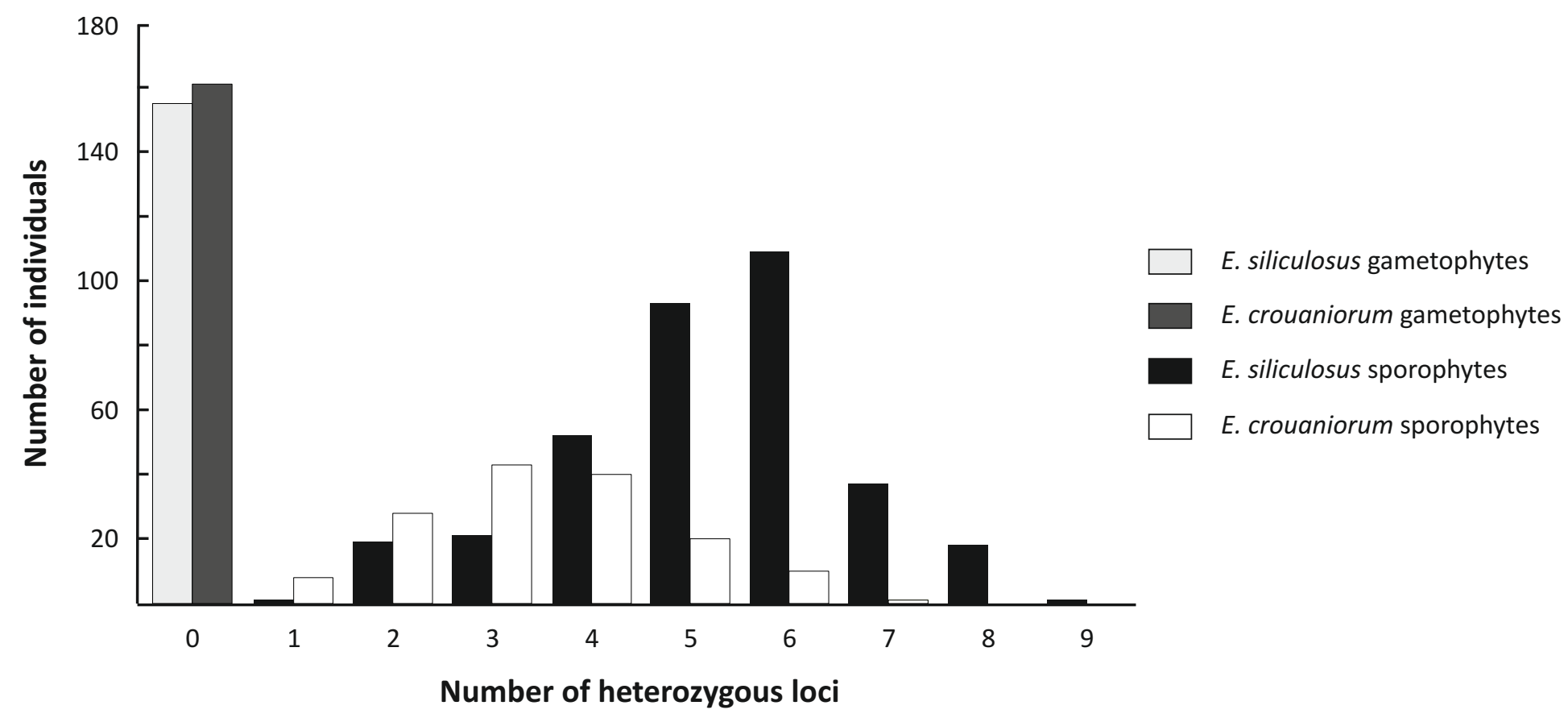




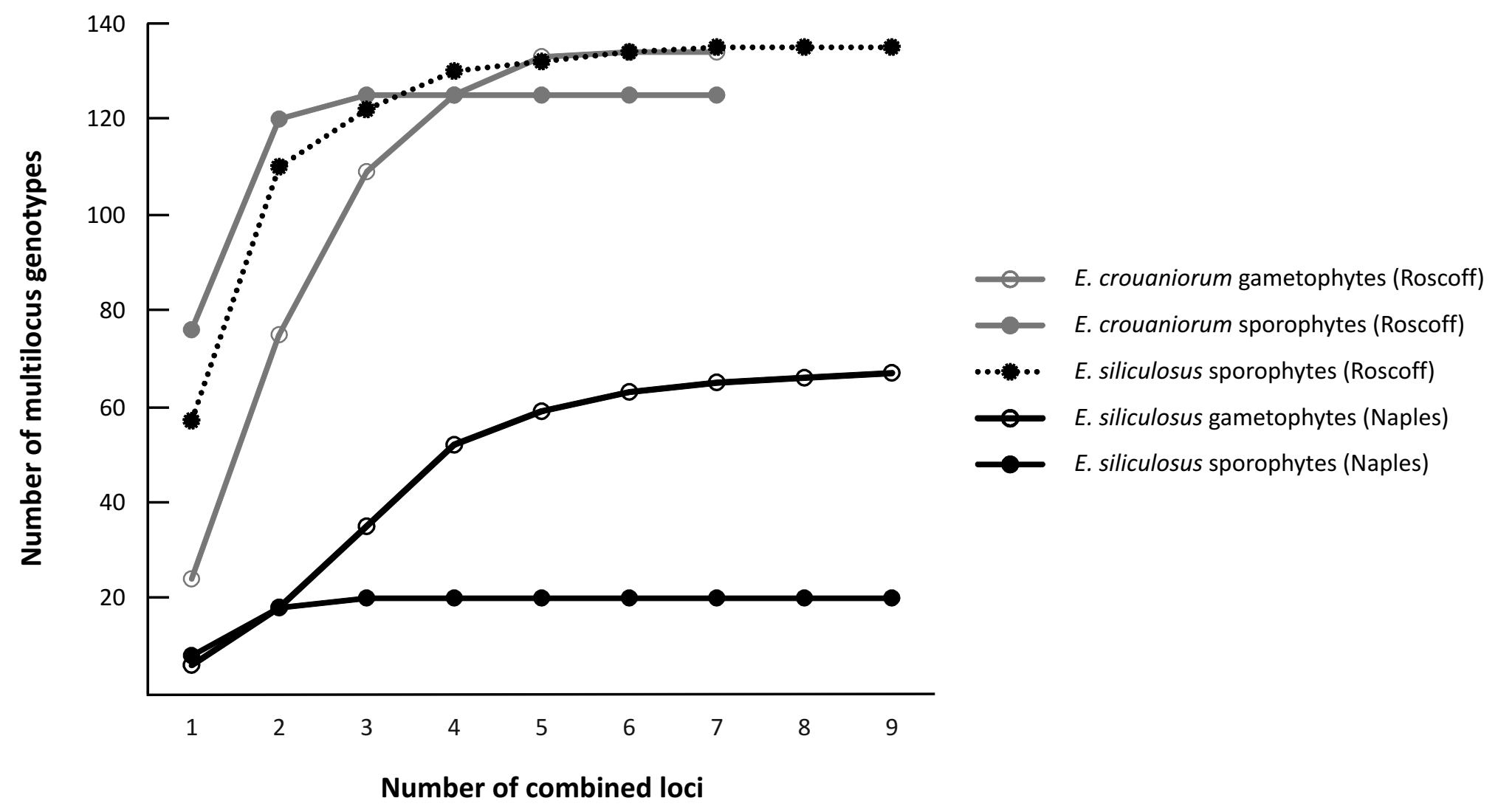

